\title{
Heidegger/Nietzsche La concepción del ser como mismidad e ipseidad
}

\author{
Heidegger/Nietzsche \\ The conception of Being as sameness and as ipseity
}

\author{
IRENE BREUER \\ (Bergische Universität Wuppertal)
}

\begin{abstract}
Resumen: Esta contribución elabora la concepción del ser en su mismidad e ipseidad en Heidegger y Nietzsche, contrastando la concepción nietzscheana de la voluntad de poder y del eterno retorno con la interpretación heideggeriana y enmarcándola dentro de su concepción del ser anterior y posterior a la Kehre. La tesis sostiene que, mientras Heidegger concibe la ipseidad ya no como identidad a sí mismo en el sentido de las egologías tradicionales, sino como modo de existencia auténtico del Dasein que se asume como tal, la concepción de Nietzsche es la inversa: la ipseidad como modo de existencia implica la renuncia a ser uno mismo y la asunción de diferencias y transformación de las fuerzas componentes. Mientras la mismidad en Nietzsche se resume al querer [Wille] como unicidad eternamente retornante, un retorno a la mismidad originaria en el sentido heideggeriano es imposible porque las diferencias son irreductibles a una pertenencia originaria de ser y pensar. Paradójicamente, el "yo" nietzscheano es propiamente él mismo, renunciando a ser él mismo: éste es el poder que lo singulariza.
\end{abstract}

Palabras Clave: identidad, subjetividad, ontología, voluntad de poder, eterno retorno

\begin{abstract}
This paper elicits the conception of the self as sameness and as ipseity in Heidegger and Nietzsche by confronting Nietzsche's conception of the will to power and eternal return with Heidegger's interpretation, while setting it within the framework of Heidegger's conception of being before and after the Kehre. It claims that, while Heidegger conceives of ipseity no longer as the self of a self-identical being in terms of the traditional "egologies" but as the proper mode of existing of Dasein that assumes itself, Nietzsche's conception is the inverse: ipseity as mode of existence implies renouncing to being oneself as sameness and assuming the fact of being composed by differences and forces in continuous transformation. While sameness in Nietzsche is restricted to the will as an eternally returning unicity, a return to the originary sameness in the Heideggerian sense proves to be impossible insofar as those differences are irreducible to a primary belonging-together of being and thinking. Paradoxically enough, the Nietzschean "I" becomes properly itself only by renouncing to being itself: this is the power that singularizes it.
\end{abstract}

Keywords: identity, subjectivity, ontology, will to power, eternal return 


\section{Introducción}

La exposición del eterno retorno tal como Nietzsche la concibe supone la crítica a la posibilidad de un equilibrio en el universo y, por lo tanto, la imposibilidad de una síntesis entre contrarios. Más aun, conlleva la anulación del pensar representativo en tanto postula la no-separación entre sujeto y objeto, ya que ambos no son sino indistintamente interpretación-interpretante, implicando el rechazo al concepto de ser. En efecto, la representación se caracteriza por convertir al hombre en «representante de lo existente en el sentido de la objetividad», en palabras de Heidegger. Y agrega: «El que el mundo se convierta en imagen, es el mismo procedimiento por el cual el hombre dentro de lo existente se convierte en subjectum» (Heidegger, 1994a, p. 87). Nietzsche rechaza toda separación entre sujeto y objeto, ser y mundo: «No hay nada más que el todo [Aber es giebt Nichts ausser dem Ganzen!]», no hay nada transcendente, nuestro "ser" pertenece al todo, está unido al todo, no hay nada que pueda medir, comparar nuestro ser (Nietzsche, Götzen-Dämmerung, KSA 6, par. 8, p. 96 y ss.). Ser y mundo conforman una totalidad indisociable; una unidad altamente inestable y temporaria de una multiplicidad de seres en lucha, que, al afirmarse a sí mismos, afirman involuntariamente al todo del cual forman parte ${ }^{1}$. Nietzsche caracteriza esta totalidad como "caos": el «carácter total del mundo [...] para toda la eternidad», en cuanto carece de «orden, articulación, forma, belleza y esencia» ${ }^{2}$. Sólo desde el punto de vista del hombre limitado este caos puede parecer indistinguible, pero Nietzsche lo ve como Dike-Necesidad, como devenir necesario, sin comienzo ni fin, que carece de toda regulación intencionada, rechazando, por ende, tanto una divinificación, como una objetivación del devenir. Caos, necesidad y eterno retorno se articulan: el caos no antecede a un movimiento circular de las fuerzas, sino que es eterno, no devenido [ungeworden], y retorna en cada círculo. Tampoco el círculo ha devenido (o tiene un origen [ein Gewordenes], sino que es la «ley primera [Urgesetz]», así como lo es la cantidad de fuerza, «sin excepción ni transgresión»»3. El devenir está impulsado por la oposición de fuerzas, cuya determinación es su necesidad, que a la vez es una interpretación: «el eterno retorno es pues, la interpretación del universo que presupone el caos» (Müller-Lauter, 1999b, p. 345). Además, como para Nietzsche el cuerpo es una organización de dominio, y el devenir es considerado desde el punto de vista de la animalidad y los instintos, el caos es entendido, no como un desorden sin ley, sino como protección frente a la riqueza apabullante del devenir (Müller-Lauter, 1999b, p. 143).

La interpretación, y no ya la relación representativa, es la que constituye un hilo de Ariadna con el cual el hombre puede tornar formulable este devenir eternamente caótico. Para el pensamiento metafísico moderno, en cambio, el caos es informulable, impensable y constituye su límite, ya que «conocimiento y devenir se excluyen» (NF

\footnotetext{
NF 1884-1885, KSA 11, 27(27), p. 282: «Am Leitfaden des Leibes erkennen wir den Menschen als eine Vielheit belebter Wesen, welche theils mit einander kämpfend, theils einander ein-und untergeordnet, in der Bejahung ihres Einzelwesen unwillkürlich auch das Ganze bejahen.»

2 Die fröhliche Wissenschaft, af. 109, KSA 3, p. 468: «Der Gesamt-Charakter der Welt ist dagegen in alle Ewigkeit Chaos, nicht im Sinne der fehlenden Nothwendigkeit, sondern der fehlenden Ordnung, Gliederung, Form, Schönheit, Wesenheit, und wie alle unsere ästhetischen Menschlichkeiten heissen.»

3 NF 1880-1882, KSA 9, 11(157), p. 502: «es gab nicht erst ein Chaos und nachher allmählich eine harmonischere und endlich eine feste kreisförmige Bewegung aller Kräfte: vielmehr alles ist ewig, ungeworden: wenn es ein Chaos der Kräfthe gab, so war auch das Chaos ewig und kehrte in jedem Ringe wieder. Der Kreislauf ist nichts Gewordenes, er ist das Urgesetz, so wie die Kraftmenge. Urgesetz ist, ohne Ausnahme und Übertretung.»
} 
1885-1887, KSA 12, 9(89), p. 382). La totalidad del mundo sólo puede ser aprehendida gracias al autoengaño de la voluntad ${ }^{4}$, por la cual ésta "cree" conocer. Este "límite de lo expresable" propio de la metafísica no consiste en un retorno a la vida instintiva, aunque «la mayor parte del pensar consciente de un filósofo est[é] guiado de modo secreto por sus instintos» (Jenseits von Gut und Böse, par. 3, KSA 5, p. 17), sino en considerar las valoraciones como ficciones regulativas útiles para la vida, es decir, en admitir su no-verdad. Implica, además, negar toda permanencia o indestructibilidad del mundo, admitir su contante devenir ${ }^{5}$, su eterna invención. Es desde este "habla del límite de lo expresable" que es posible asumir el caos como ficción y así evitar la reducción de la multiplicidad de fuerzas a un nuevo principio.

Estas aseveraciones se diferencian de la lectura heideggeriana de Nietzsche, que interpreta la noción de eterno retorno como «un enunciado sobre el ente en su totalidad», como «la última posición metafísica fundamental en el pensamiento occidental» (Heidegger, 2000a, pp. 212 y 214), o como un retorno infinito de una secuencia finita de eventos en su mismidad ontológica. Por el contrario, el pensamiento nietzscheano no plantea el retorno de la identidad del ciclo ni de la permanencia del ser en su mismidad, sino el retorno de la unidad de un devenir cambiante y de un "ser" en tanto multiplicidad irreductible, que se sabe interpretación. En efecto, sólo los «cortos de vista» encuentran una permanencia en el mundo, una «tierra firme en el mar del devenir» (Die Philosophie im tragischen Zeitalter der Griechen, 4-5, p. 823). En cambio, el hombre que afirma el retorno de lo mismo simultáneamente lo recrea y transforma (“Auf den glückseligen Inseln", Also sprach Zarathustra II, KSA 4, p. 110).

Cabe aquí hacer una distinción: la repetición en sentido estrecho fundamenta la posibilidad de la representación, en sentido amplio, en cambio, inaugura la diferencia, la que escapa a la representación por estar inscripta en un proceso de alteración constante y continuo. En este sentido, Nietzsche y Kierkegaard coinciden en afirmar que la repetición en el seno de la identidad es imposible. Por un lado, como sostiene Nietzsche, el olvido de los viejos valores es necesario para poder recrearlos en un nuevo comienzo ("Von den drei Verwandlungen", Also sprach Zarathustra I, KSA 4, p. 31). Por el otro, Kierkegaard descubre que al repetir se inaugura por medio de la praxis una nueva acción diferenciada de la primera: «Lo único que se repitió fue la imposibilidad de la repetición" (Kierkegaard, 1976, p. 199). La repetición que origina la diferencia no es, pues, reductible a un sistema conceptual ni admite distribuciones fijas, sino que se caracteriza por una variación incesante. Por ende, la afirmación de la repetición idéntica de la multiplicidad irreductible genera paradójicamente diferencias sometidas a un eterno devenir. La repetición, concluye Kierkegaard, «es el interesse de toda metafísica, pero al mismo tiempo es el interés en el que la metafísica naufraga» (Kierkegaard, 1976, p. 161).

En la interpretación de Heidegger, por el contrario, Nietzsche lleva a cabo el cumplimiento de la metafísica: «el pensamiento de Nietzsche, en conformidad con todo el pensamiento de Occidente desde Platón, es metafísica». La metafísica intenta dar respuesta al qué es y cómo es el ente en su totalidad, pregunta respondida en Nietzsche a

${ }^{4}$ NF 1885-1887, KSA 12, 9(89), p. 382: «Folglich muss „Erkenntnis“ etwas anderes sein: es muss ein Wille zum Erkennbar-machen vorangehn, eine Art Werden selbst muss die Täuschung des Seienden schaffen.»

5 NF 1885-1887, KSA 12, 9(89), p. 826: «Die Dinge selbst an deren Feststehen und Standhalten der enge Menschen- und Thierkopf glaubt, haben gar keine eigentliche Existenz, sie sind das Erblitzen und der Funkenschlag gezückter Schwerter [...] im Kampfe der entgegengesetzten Qualitäten.» 
través de las nociones de voluntad de poder y eterno retorno. Las cinco «expresiones fundamentales» de Nietzsche (voluntad de poder, nihilismo, el eterno retorno de lo mismo, el superhombre, la justicia) corresponden a los cinco puntos fundamentales de la metafísica, que se corresponden y articulan entre sí de la siguiente manera:

"La voluntad de poder" es la expresión para el ser del ente en cuanto tal, la essentia del ente. "Nihilismo" es el nombre para la historia de la verdad del ente así determinado. "Eterno retorno de lo mismo", se llama al modo en que es el ente en su totalidad, la existentia del ente. "El superhombre" designa a aquella humanidad que es exigida por esta totalidad. "Justicia" es la esencia de la verdad del ente como "voluntad de poder" (Heidegger, 2000b, pp. 209-211).

La voluntad de poder, que es el poder incondicionado del Querer (Heidegger, 2000b, p. 213), constituye la esencia del ente. El ente afirma sus caracteres en la concepción del eterno retorno, el cual no puede sino querer retornar eternamente, ésta es «su posición metafísica fundamental» (Heidegger, 2000a, p. 211). Para Heidegger, Nietzsche no supera la metafísica, sino que, en la unidad de su pensamiento, constituye su acabamiento, y a su vez, su tragedia: «con el pensar del pensamiento del eterno retorno lo trágico en cuanto tal se convierte en el carácter fundamental del ente» (Heidegger, 2000a, p. 299). Nietzsche recurre a la controversia con el pensamiento platónico-cristiano y a su consecución en la modernidad (Heidegger, 2000a, p. 213).

En este contexto, interesa a este trabajo no sólo la contraposición y esclarecimiento de ambas posiciones en torno al ser y a la identidad, sino examinar las nociones de mismidad e ipseidad implicadas en ellas. Para ello, se delineará el marco conceptual heideggeriano en el cual se enmarca la crítica a Nietzsche, para esclarecer la concepción de mismidad e ipseidad con anterioridad y posterioridad a la Kehre. A continuación, se analizará en primer lugar la interpretación heideggeriana de la subjetividad en Nietzsche, para luego analizar su articulación como voluntad de poder y eterno retorno, su relación con la verdad y la noción de identidad, para concluir con el esclarecimiento del sí mismo en ambos planteos con recurso a la distinción entre mismidad, ipseidad y diferencia planteada por Heidegger en sus escritos anteriores y posteriores a la Kehre. La tesis sostiene que, mientras en Heidegger la ipseidad es concebida ya no como identidad a sí mismo según las egologías tradicionales, sino como modo de existencia, la temporalidad del "haber sido propio" implica una reiteración, por la cual el Dasein se vuelve sobre su condición de yecto y asume o toma sobre sí el ente que ya es, es decir, su propio modo de existir auténtico. En Nietzsche, por el contrario, la ipseidad como modo de existencia consiste en asumir el haber-sido y el por-ser, implica renunciar a ser uno-mismo y aceptar la transformación de la multiplicidad de las fuerzas que me componen. La mismidad en Nietzsche se resume al querer, al Wille que, como co-pertenencia de las diferencias constitutivas de las fuerzas, idéntico a sí mismo retorna eternamente. Mientras en Heidegger, la pérdida y el olvido de sí mismo mientan una existencia inauténtica que se pierde a sí misma en la cotidianeidad, en Nietzsche, por el contrario, esta pérdida caracteriza su "ser" auténtico y voluntariamente querido en aras de posibilitar su recreación. Un retorno a la mismidad originaria en el sentido heideggeriano es imposible porque, por un lado, las diferencias no admiten una distribución fija, y por el otro, son irreductibles a una pertenencia de ser y pensar originaria. Paradójicamente, el "yo" nietzscheano es propiamente él mismo, renunciando a ser él mismo: éste es el poder que lo singulariza. 


\section{Marco conceptual de la crítica heideggeriana: mismidad, ipseidad y diferencia}

Antes de entrar en el desarrollo de estas cuestiones, es necesario esclarecer el marco conceptual en el que están insertas. Ya en Ser y Tiempo de 1927 Heidegger rechaza la concepción del alma como sustancia, del yo como subjectum, en una palabra, las ontologías tradicionales ${ }^{6}$. En ellas, el concepto de sujeto no caracteriza a la ipseidad [Selbstheit], «el "ser sí mismo" del yo qua "sí mismo", sino la mismidad [Selbigkeit] y constancia [o permanencia] [Beständigkeit] de algo siempre ya "ante los ojos" [o simple estar-ahí] [Vorhandenen]» (Heidegger, 1999, p. 347). A la pregunta por el ser como fundamento de vivencias y como permanencia, el «"qué" [Was]», Heidegger opone la pregunta por el ser que en cada caso es existiendo, el «"quién" [Wer]» (Heidegger, 1999, p. 57) o Dasein. El Dasein o "Ser-ahí" se funda en el «"estado de ser en sí mismo" [o mantenimiento de sí] del "sí mismo" existente ["Selbständigkeit" des existierenden Selbst]» (Heidegger, 1999, p. 330). La tesis de Heidegger plantea, por lo tanto, que la ipseidad —el ser sí mismo - es una «manera de ser del Dasein, una manera, para ese ente, de relacionarse consigo mismo y con su ser» (Romano, 2017, p. 336), reviste, por ende, el carácter de un existenciario (Heidegger, 1999, p. 147). La ipseidad designa el modo en que el Dasein existe en modo propio [eigentlich] cuando se hace cargo de su existencia, asumiendo su propio ser (Heidegger, 1999, p. 146). El poder ser propio permite captar el mantenimiento de sí mismo [Selbst-ständigkeit], que se alcanza en la resolución precursora. El Dasein «es propiamente sí mismo [eigentlich selbst]» en cuanto asume a la propia muerte como la posibilidad más propia. Este poder ser propio que nos singulariza, esta existenciaridad, «da la constitución ontológica del "estado de ser en sí mismo [Selbst-ständigkeit]" del "Ser-ahi"” (Romano, 2017, p. 350). Por ello, «el "Ser-ahí" no dice "yo" [para Heidegger un simple «índice formal» (Heidegger, 1999, p. 132)] sino que "es"» (Romano, 2017, p. 350). Es gracias a esta comprensión de la ipseidad en tanto modo de existir que, para Heidegger, «la "mismidad" [Selbigkeit] del "sí mismo" existente [eigentlich existierenden Selbst $]$ está [...] separada por un abismo ontológico de la identidad del yo que se mantiene en medio de la multiplicidad de las vivencias» (Heidegger, 1999, p. 147). La mismidad [Selbigkeit] y la ipseidad [Selbstheit] del sí mismo se revelan como respuestas a la pregunta por el "quién" y se articulan en «una pluralidad de maneras "subjetivas" de ser» (Greisch, 1994, p. 166). La ipseidad, en tanto manera subjetiva de existir, se distingue de la mismidad como permanencia de una esencia invariable. Aquí encontramos el primer paso de una des-ontificación de la ipseidad y el acento en la dimensión temporal de la existencia.

El desarrollo de la pregunta por el ser conduce a Heidegger a una "vuelta" [Kehre], que se manifiesta por primera vez en las conferencias dadas en 1930 bajo el título de De la esencia de la verdad. Allí enfoca esta pregunta a partir no ya del ser del ente, sino del tránsito del tiempo al ser, un salto bajo la conducción de la libertad como esencia de la verdad, que constituye al Dasein en libertad para el ser [Sein], (Heidegger, 1948). Es en los Aportes a la filosofía de 1936 donde esta pregunta por la verdad del ser se desarrolla a partir del ser en su propia historicidad, para el cual Heidegger acuña el término de "Seyn". Aquí, el Seyn despliega su plena esencia como evento de la fundación del "ahí", una fundación que, por un lado, posibilita la transformación del ser humano y por el otro, el acontecer histórico de la verdad. La idea de un ser [Seyn] que acontece al Dasein se confunde con el acontecimiento [Ereignis] como proceso

Cfr. Walton, 2001, para un análisis detallado, realizado dentro del marco de un examen de las diversas figuras de la identidad en la fenomenología post-husserliana. 
de automanifestación del mismo Seyn - una concepción que rompe definitivamente con la hipótesis de un ego autosuficiente (Heidegger, 2003, cfr. Tengelyi, 2017) - La reflexión en torno al ser caracteriza también el período entre 1936 y 1940, donde se ubican las lecciones dictadas en la Universidad de Friburgo sobre Nietzsche, que se extienden hasta 1946. En Nietzsche la pregunta por el ser del ente devela a la voluntad de poder como la verdad del ente, mientras el ser "es" como eterno retorno de lo igual.

En sus Conceptos Fundamentales, dictados en la misma universidad en 1941, el concepto de mismidad ya no mienta un modo de ser impropio del Dasein, sino una determinación del ser mismo. Heidegger distingue aquí la mismidad de la igualdad: para que haya «lo Mismo sólo se precisa de unicidad», mientras que para que haya «lo Igual hacen falta cosas distintas y múltiples». Mientras la mismidad del ser reúne en sí las determinaciones del ser, es decir, aquello de lo cual el ser se diferencia — ser y pensar, ser y apariencia, ser y devenir-, la igualdad implica una comparación entre entes diversos. El ser, que es «diferente en cada caso en sí y de suyo [...], se distingue por la unicidad, y fuera de ésta, el ente en su multiplicidad» (Heidegger, 1994b, p. 88). Heidegger resume los diferentes modos de entender la identidad de la siguiente manera:

Lo mismo [das Selbe] no se corresponde con lo igual [dem Gleichen], tampoco con la vacía unidad de lo meramente idéntico [Identischem]. Lo igual se desplaza siempre a lo indiferenciado [Unterschiedslose], para que todo coincida con él. Lo mismo es, por el contrario, la co-pertenencia mutua de lo diferente a partir de la reunión operada por la diferencia. Lo mismo se deja decir solamente, cuando la diferencia [Unterschied] es pensada. [...] Lo mismo prohíbe cualquier intento de nivelar (igualar) a lo diverso [Verschiedene] con lo igual. Lo mismo reúne lo diferenciado en una unicidad originaria [ursprüngliche Einigkeit] (Heidegger, 1967, p. 67).

La diferencia del ser es, pues, interna, propia de la unicidad del ser, mientras que la diferencia del ente es externa, propia de entes diversos y múltiples. Es posible distinguir entonces entre la diferenciación inmanente al ser y la heterogeneidad trascendente de los entes. Esta concepción de la Mismidad es posteriormente concebida en términos de mismidad originaria en los escritos publicados en 1957 bajo Identidad y Diferencia, donde Heidegger indaga en la esencia de la metafísica.

Mientras en Ser y Tiempo, el sentido del ser se comenzó a leer a partir de un ente determinado en tanto Dasein, en Identidad y Diferencia este sentido se busca en la esencia de la metafísica para lo cual se requiere dar un «paso atrás» hacia «lo impensado» por ella, el olvido de la diferencia entre ser y ente (Heidegger, 1990, p. 115). Para ello se debe retroceder hasta la co-pertenencia de ser y del hombre, de ser y pensar en una «identidad» cuya esencia es este pertenecer originario que Heidegger denomina Ereignis o «acontecimiento de transpropiación» (Heidegger, 1990, 91). Mientras la identidad según la entiende la metafísica heredada concibe a la identidad como rasgo del ser, al ser como permanencia y a la identidad como lo permanentemente igual consigo mismo, Heidegger considera que la identidad alberga desde siempre una duplicidad, una diferencia entre ser y hombre, las cuales se transpropian en el Ereignis originario, donde se introduce la diferencia entre ser y ente, fundamento de la concepción ontoteológica de la metafísica, diferencia que permanece impensada (Heidegger, 1990, p. 133).

Heidegger parte del análisis del principio de identidad. El principio de identidad "A = A" habla del ser de lo ente. Este principio no dice que cada "A" es él mismo el mismo, sino más bien, esta fórmula dice que cada algo es con sí mismo lo mismo, es decir, «a cada ente en cuanto tal le pertenece la identidad, la unidad consigo 
mismo». En efecto, la igualdad entendida como uniformidad indicaría la indiferencia de una identidad vacía y aplicable a cualquier cosa. Esto es lo que tradicionalmente se piensa, a saber, «que la unidad de la identidad constituye un rasgo fundamental en el ser de lo ente». Pero a la identidad entendida como igualdad se opone la identidad como pertenencia, aquella que «habla desde el ser de lo ente» (Heidegger, 1990, p. 67). Heidegger interpreta la identidad del ser en términos de «mismidad como mutua pertenencia [Selbigkeit als Zusammengehörigkeit]». Este "como" remite al ser o a la verdad del ente, pero requiere también un pensar. «Pensar y ser tienen su lugar en lo mismo y a partir de esto mismo se pertenecen mutuamente», éste es el sentido de la frase de Parménides (Heidegger, 1990, p. 69). En efecto, el ente no sería tal, si no fuera pensado como "lo que es". Por lo tanto, «el ser pertenece juntamente con el pensar a la identidad» (Pöggeler, 1994, p. 146).

La Mismidad alberga desde siempre una diferencia entre ser y hombre, los cuales se transpropian en el Ereignis originario. El Ereignis produce así la diferencia entre ser y ente, fundamento de la concepción ontoteológica de la metafísica. La diferenciación entre ser y ente «es, inicialmente, lo que esencia del ser mismo, cuya inicialidad es el acaecimiento apropiante [Ereignis]» (Heidegger, 2000b, p. 404). La diferencia entre ser y ente proviene de la mismidad originaria. Ser y ente son por lo tanto lo Mismo, en la Mismidad que reúne esta duplicidad en unidad. «El ser no es algo otro que lo ente, si fuera algo otro, entonces sería nuevamente un ente - y la diferencia ontológica se transformaría en meramente óntica-》 (Pöggeler, 1994, p. 150). Ser y ente son, por lo tanto, lo Mismo, en la Mismidad originaria que reúne esta duplicidad en unidad. En conclusión, mientras la diferencia entre ser y ente es ontológica, la alteridad o heterogeneidad entre entes es óntica.

El concepto de Mismidad [Selbigkeit] adquiere aquí otro sentido: ya no se trata de la identidad como constancia de un ser que existe de manera impropia en los términos de Ser y Tiempo, sino de la identidad como pertenencia mutua de ser y pensar. Pueden inferirse una serie de oposiciones: en Ser y Tiempo, a la constancia y mismidad de un yo sustancia como permanencia se opone la ipseidad en tanto mantenimiento de sí mismo en la propiedad, como manera de existir. Ya con posterioridad a la Kehre, a la mismidad en tanto pertenencia mutua de ser y pensar originaria, se opone la igualdad como identidad vacía de determinaciones. Por otro lado, a la diferencia en tanto diferenciación inmanente al ser se opone la heterogeneidad y mutua alteridad de los entes. Esta distinción remite a su vez a una diferencia "anterior" entre ser y ente que surge a partir de una Mismidad originaria en el acontecimiento de transpropiación [Ereignis]. Es desde el conjunto de reflexiones posteriores a la Kehre, pero con miras a las distinciones tempranas que Heidegger plantea su crítica a la subjetividad moderna, entre cuyos exponentes incluye a Nietzsche.

\section{La voluntad de poder: ¿esencia del ente en cuanto tal o ficción útil?}

En su análisis de la subjetividad en Nietzsche, Heidegger plantea una comparación con la subjetividad en Descartes. Esta comparación revela los presupuestos de Heidegger al abordar su análisis: Heidegger asigna el carácter de consciencia a la voluntad de poder para poder no sólo relacionarla con la idea de la subjetividad moderna, sino también establecer la filosofía de Nietzsche como su acabamiento. En la subjetividad moderna la consciencia tiene la función de esclarecimiento y de dación de unidad de los objetos dados en la percepción con el objetivo de posibilitar la experiencia. 
Heidegger (2000b, pp. 156 y ss.) enlista en cuatro puntos las coincidencias o paralelos entre Descartes y Nietzsche:

a) el hombre cartesiano es sujeto en el sentido de la «yoidad» representadora, mientras que el hombre para Nietzsche es tal en el sentido de este «fatum último» que es su cuerpo;

b) el ser del ente se articula en la relación entre la representatividad, que remite al sujeto que representa, y la objetualidad del objeto representado. Para Nietzsche, en cambio, el ser es representatividad en la medida en que estatiza con una apariencia lo que es deviniente. Es la voluntad de poder la que constituye el ser (fijo) del devenir;

c) la verdad para Descartes mienta certeza, mientras que, para Nietzsche, es un «tener-por-verdadero», que a su vez implica un fijar lo que deviene.

d) para Descartes el hombre es la medida de todo ente en la representación. Para Nietzsche, toda conformación es producto y propiedad del hombre en cuanto que es la voluntad de poder quien instaura las perspectivas desde las cuales se configura el mundo.

Para Heidegger, Nietzsche modifica la concepción de verdad como valor, que radica en la utilidad para la vida: «lo que pensamos, en cuanto pensado, sólo es verdadero en la medida en que sirve a la conservación de la voluntad de poder» (Heidegger, 2000b, p. 151). Sin embargo, el aparente repudio del cogito presente en la voluntad de poder no sería sino un vínculo aún más estrecho con la subjetividad cartesiana. Para este autor, Nietzsche coincide con Descartes en la consideración de que las categorías surgen del pensar, coincide pues en aquello en lo cual cree distanciarse, y se distancia sólo en el modo en que esto ocurre: no se trataría de una certeza inmediata, sino de la operación de una voluntad de poder calculadora y creadora de valores. Nietzsche, pues, aceptaría la noción de sujeto de Descartes, pero relativizaría la verdad tolerándola como un «error necesario», pues la representación fija en una apariencia de detención lo que es deviniente, no lo muestra «como es» (Heidegger, 2000b, p. 152). En estas expresiones se presupone la verdad como concordancia del conocimiento que el sujeto tiene con lo real.

Esta necesidad del error útil se extiende a la lógica, pues ésta es necesaria como forma de ordenamiento, como «un instrumento de la voluntad de poder». Nietzsche no haría sino continuar con los planteos cartesianos, en la medida en que la misma voluntad de poder es instauradora y calculadora de valores, de igual modo que la yoidad de la consciencia pensante en Descartes. Lo que comparten es la noción de «subjectum» (el yo pensante en Descartes, el cuerpo en Nietzsche), con lo cual se traslada el ámbito fundante desde la consciencia a las pulsiones de la voluntad de poder (Heidegger, 2000b, p. 153). La caracterización misma de la voluntad de poder le impediría a Nietzsche acceder a la esencia de la metafísica, a su ser. Pues la voluntad de poder es para Nietzsche «la esencia más íntima del ser» (Heidegger, 2000b, p. 214) — tiene, por lo tanto, carácter metafísico-.

En la interpretación de Heidegger, la voluntad de poder calcula sus propias condiciones de incrementación; es decir, ella «ordena», «dispone sobre posibilidades» para «autosuperarse»: la voluntad de poder es la esencia del ente en cuanto tal (Heidegger, 2000 b, p. 215). La voluntad de poder quiere a instaura valores para asegurarse su intensificación: «la verdad es un valor necesario para la voluntad de poder» (Heidegger, 2000 b, p. 254). Lo verdadero implica paradójicamente lo falso en cuanto al ente, pues lo representa en tanto no es, es decir, en tanto fija lo que deviene. La voluntad es 
esencia de todo lo que es y, por lo tanto, se convierte en «el principio de la posición de valores». La verdad como pensamiento de la voluntad de poder, es un «pensar según valores». Este pensar según valores constituye para Heidegger la «auto-consciencia» de la voluntad de poder, como el «contar consigo mismo que ejerce y da poder». De este modo, el pensamiento de valores constituye la identidad de la voluntad de poder, según el modo en el cual ella es subjectum (como fundamento, basada en sí misma). La voluntad de poder se transforma en subjetividad que piensa o calcula en términos de valor (Heidegger, 2000b, pp. 220 y ss.).

Nietzsche critica esta presunción de consciencia autónoma, pues ella, por el contrario, no es una zona objetiva, estable, sino que adopta formas provisionales, que surgen de la momentánea configuración de fuerzas, eternamente cambiantes, en las que se plasma el mundo. La consciencia ya no es aquella que trae a sí, o se representa, los objetos del conocimiento, apropiándose de ellos al fijarlos en categorías, sino que es aquella ficción, cuya fuerza inventiva genera las categorías para logicizarlas, es decir, tornarlas comprensibles (cfr. NF 1885-1887, KSA 12 (11), p. 237). Sólo en el sentido de «ficción regulativa» puede entonces hablarse de una consciencia que, en función de la necesidad de seguridad y abreviación, genera formas efímeras que tienen el carácter de «errores útiles»: «En realidad, la lógica (al igual que la geometría y la aritmética) es valiosa sólo por las verdades ficticias, que nosotros hemos creado. La lógica es el intento de comprender al mundo real, según un esquema de ser [Seinsschema] establecido por nosotros, para tornarlo más correcto, formulable, calculable» (NF 1885-1887, KSA 9(97) (67), p. 391).

La consciencia caracterizada de este modo resulta por lo tanto inadecuada como lugar dese el cual se juzga al sujeto moderno, como destaca M. Cragnolini (1998a, p. 184). La asignación de una autoconsciencia a la voluntad de poder constituiría, pues, un presupuesto de Heidegger en su análisis de Nietzsche, necesario para situar al pensador en el acabamiento de la metafísica. Otro de los presupuestos presentes en Heidegger concibe a la unidad de la voluntad de poder como constituyente de la esencia del ente que existe como eterno retorno de lo mismo. La voluntad de poder da consistencia a lo que carece de ella, es decir, al devenir (Heidegger, 2000b, pp. 230-235). Sin embargo, "la" voluntad de poder no existe para Nietzsche, sino sólo la multiplicidad de voluntades de poder que en su constante lucha por el poder cambian, agregándose y desagregándose, y que sólo en virtud de la lucha simulan su unidad y simplicidad?

\section{Nietzsche: "Selbst" como cuerpo}

Para Nietzsche, el «yo», al igual que el resto de otros «schemata» como materia, cosa, sustancia, etc., es una «construcción del pensar». En realidad, estas nociones no son más que categorías lógico-gramaticales que permiten la elaboración de un aparato falsificador pero necesario para la construcción de ficciones útiles para la vida. La noción de «ficción regulativa» (NF 1884-1885 KSA 11 35(35), p. 526) implica que la verdad no es sino una ilusión que fija el devenir, estatizándolo en categorías que se postulan como necesarias: en efecto, estas ficciones son necesarias para la vida, pero al

Cfr. NF 1887-1889, KSA 13, 11(73) (331), p. 36: «—: es giebt keine dauerhaften letzten Einheiten, keine Atome, keine Monaden: auch hier ist „das Seiende“ erst von uns hineingelegt, (aus praktischen, nützlichen, herrschaftlichen Centren „Vielheiten“ jedenfalls, aber die „Einheit“ ist in der Natur des Werdens gar nicht vorhanden». Ver también respecto a la crítica a la interpretación heideggeriana, Müller-Lauter, 2000, pp. 135-193. 
mismo tiempo, son falsas. Son fabulaciones relativamente necesarias para la comunicación, con el propósito de definir, entender y explicar. Es más,

b) Si se ha comprendido que el "sujeto" no es nada que opera [was wirkt], sino una ficción, se siguen variadas consecuencias: [...] hemos imaginado la objetualidad [Dinglichkeit] bajo el modelo del sujeto, y la hemos reinterpretado en el caos de las sensaciones. Si no creemos más en el sujeto operante [wirkendes Subjekt], también cae la creencia en las cosas operantes [wirkende Dinge], en efectos recíprocos [Wechselwirkung], causa y efecto, entre aquellos fenómenos, a los cuales llamamos cosas [...].

c) Si renunciamos al sujeto operante, también debemos renunciar al objeto, sobre el cual se opera un efecto [auf das gewirkt wird]. La duración, la igualdad consigo mismo, el ser, no inhieren ni en el sujeto ni en aquello que es llamado objeto: ellos son complejos del acaecer [Complexe des Geschehens], aparentemente duraderos en relación a otros complejos - como por ejemplo, por una diferencia en el tiempo del acaecer (reposo-movimiento, firme-suelto: todas contradicciones, que no existen en sí mismas y con las cuales de hecho sólo se expresan diferencias de grado [Gradverschiedenheiten] - , que en una cierta medida, desde la óptica con la que se mire, se presentan como contradicciones (NF 1885-1887, KSA 12, 9(91), pp. 383 y ss.).

Para Nietzsche, los productos del pensar son construcciones de un sujeto ficcional, pero este acto de pensar parece ahora ser verdadero, el fundamento de estas ficciones: «un pensamiento viene, cuando "él" quiere, y no cuando "yo" quiero». Se debería decir: «ello piensa». Lo que en principio podría interpretarse como una mera inversión, se revela como una destrucción de supuestos: este "ello" no constituye una certeza inmediata (Jenseits von Gut und Böse, KSA 5, par. 16, pp. 29 y ss.), sino que es «una interpretación del proceso y no forma parte del mismo» (Jenseits von Gut und Böse, KSA 5, par. 17, pp. 30 y ss.). El pensamiento ya no es considerado como uno de los atributos «que me pertenecen: únicamente él no puede ser separado de mí» (Meditaciones Metafísicas, AT IX, 22-23, 2da. Meditación, en Descartes, 1967, p. 226), como afirma Descartes, sino que se torna independiente de mi voluntad, es decir, ajeno a mi ser. El pensamiento es, pues, uno de los componentes de la exterioridad que me atraviesa, del cruce de fuerzas que inciden en mi cuerpo.

En Nietzsche, el sí mismo se constituye como Selbst, como cuerpo, que Nietzsche opone al yo o alma [Ich]. El cuerpo, por lo tanto, se constituye en el "sujeto", «el saber de la corporalidad es el sí mismo, es decir, el cuerpo como construcción de la voluntad de poder [Herrschaftsgebilde]. Aquel sujeto aséptico del cartesianismo [...] está ahora atravesado por dolores, enfermedades, placeres». El dolor permite el acceso a lo que ha sido ocultado por el peso de la metafísica: el cuerpo como «gran razón», como pluralidad de fuerzas (cfr. Cragnolini, 1998b, pp. 113 y ss.), como agregaciones y desagregaciones de la voluntad de poder. Lo real, es el dolor, como expresa Nietzsche en La Gaya Ciencia: «el arte de la transfiguración es por cierto filosofía. No tenemos la libertad de separar alma y cuerpo, como el pueblo lo hace, tenemos aun menos libertad de dividir entre alma y espíritu. Debemos dar luz a nuestros pensamientos de nuestro dolor. [...] El dolor es el último liberador del espíritu, el maestro de la gran sospecha» (Die Fröhliche Wissenschaft, KSA 3, pp. 349 y ss.).

Cragnolini propone entonces el entender la subjetividad en Nietzsche desde su constitución como «Zwischen», como entrecruzamiento de fuerzas. En este "entre" se cruza todo aquello que fue calificado como "exterioridad" por la subjetividad moderna: el afuera, las circunstancias, los "otros", la historia, el cuerpo. En él, desaparece el binarismo sujeto-objeto, la subjetividad se configura desde la pluralidad (Cragnolini, 2000, p. 236). Pero no sólo de "exterioridad" en el sentido moderno está compuesto este cruce de fuerzas, sino de una exterioridad "ampliada": los propios pensamientos, 
deseos, voliciones y sentimientos que en Descartes son parte de la propia naturaleza de la res cogitans forman parte de este cruce (cfr. Breuer, 2012). El cuerpo como Selbst, como exterioridad, es entonces atravesado por esta multitud de fuerzas también exteriores, las que han "vaciado" de contenido a este "Selbst" que ahora, cual máscara, se reduce a una superficie, a los pliegues de la piel (cfr. Die Fröhliche Wissenschaft, KSA 3, p. 352).

Paradójicamente, a pesar de criticar la noción moderna de sujeto, Nietzsche habla en nombre propio y a través de su cuerpo en una escritura autobiográfica. Sin embargo, como analiza J. Derrida en la obra de P. de Man, esta escritura implica no sólo una estructura especular, el escribir sobre sí mismo, sino a su vez la imposibilidad de totalización de la memoria, de reunir el sí mismo en una unidad (Derrida, 1998a, pp. 35 y ss.). Es por ello que el hablar en nombre propio es "impropio", pues este sí mismo es atravesado por las otras fuerzas, las circunstancias, etc., indicando tanto una polisemia del nombre (los muchos nombres de Nietzsche), como también una imposibilidad de reunificación en una unidad de sentido.

Por ende, el "sujeto" como "Ich" es una ficción producida por el pensamiento, que lejos de conformarse en fundamento, es sólo una interpretación del proceso por el cual se comparan estados actuales con pasados para poder llegar a la conclusión del "yo pienso". En su crítica a la autoconsciencia, Nietzsche avanza aún más: este ego no es sino un «fantasma» (Morgenröthe, KSA 3, par. 105, pp. 92 y ss.), una construcción social con raíces lingüísticas - la obligación de mentir según un sistema de metáforas aceptadas - y disciplinares - la comunicación de nuestras necesidades hace que debamos conocer, aunque de modo superficial, a los otros (cfr. Vattimo, 1991, p. 125). La autoconsciencia es, en realidad, una imagen de nosotros mismos que nos devuelven los otros, nuestro "egoísmo" es entonces aparente, pues lo que creemos hacer por nuestro "yo" es hecho por un fantasma creado por otros, razón por la cual todos los sujetos viven en un medio de opiniones impersonales y valores arbitrarios, donde el error es necesario como necesidad de enmascaramiento en aras de la supervivencia (cfr. Die Fröhliche Wissenschaft, KSA 3, af. 361, "Vom Probleme des Schauspielers", pp. 608 y Ss.), en un mundo también devenido ficción lógica (Jenseits von Gut und Böse, KSA 5 , par. 4, pp. 18 y ss.), una "apariencia", sin la cual el hombre no podría vivir. El aforismo 54 de la Gaya Ciencia indica la crisis de la subjetividad y la destrucción de los supuestos del cogito cartesiano:

La consciencia de la apariencia [Schein] [...] súbitamente me he despertado en medio de este sueño, pero sólo a la consciencia de que sueño y que debo seguir soñando, para no sucumbir [...] ¡Qué es para mí ahora "apariencia"! En verdad, no el contrario de alguna esencia - qué puedo expresar de alguna esencia, ¡más que predicados de una apariencia! - [...] La apariencia es para mí lo operante y lo viviente mismo, el que en burla de sí mismo me permite sentir, que aquí no hay más que apariencias y fuegos fatuos y danza de espíritus y nada más (Die Fröhliche Wissenschaft, KSA 3, af. 54, pp. 416 y ss.).

La superficialidad de la consciencia no abre a ningún otro fundamento último, sino a la necesidad de replantearse el rol de la verdad y del ser en una vida que por necesidad de logicización debe crear fundamentos y sentidos provisorios. Se debe «mantener la duración de este sueño» (Die Fröhliche Wissenschaft, KSA 3, af. 54, pp. 416 y ss.), sabiendo que se sueña, para así no sucumbir. La mentira es necesaria, sólo así puede mantenerse el sueño de aquellos que reconocen que todo lo vivo, toda identidad y mismidad, no es sino apariencia, locura y danza de espíritus. 


\section{El eterno retorno: ¿determinación del ente en su totalidad o concepción del ser como devenir?}

El eterno retorno, según Heidegger, es el modo en que presencia el todo del ente, es la determinación del ente en su totalidad, es decir, designa el cómo de su existencia (Heidegger, 2000a, p. 212), aunque, como reconoce Heidegger, Nietzsche no haya nunca hablado en estos términos. Sin embargo, Heidegger designa con esta expresión a todo aquello que «no es simplemente nada», «aquello por lo que se pregunta» (Heidegger, 2000a, p. 228). El término «ente» tiene varias acepciones:

a) lo que deviene, se genera y corrompe pues ya no es o todavía no es nada;

b) la apariencia, el parecer, y el engaño y lo falso, pues si no fuera ente no podría engañar;

c) su límite: lo no-ente, lo que pertenece al ente en su totalidad en la medida en que sin él no habría nada alguna (Heidegger, 2000a, p. 228).

Nietzsche, sin embargo, alude al todo como «mundo», como «Dasein» o existencia, nociones que, a diferencia de Heidegger, no encierran ninguna verdad, sino sólo falsedad, ilusión, pero que, en su carácter de ficciones, son necesarias para la logicización de la vida.

En la interpretación heideggeriana, el eterno retorno de lo mismo es uno de los modos en que es el ente en su totalidad, siempre que se conciba la esencia del ente como voluntad de poder. En efecto, Nietzsche adjudica al devenir el carácter de ser como voluntad de poder: «Imprimir al devenir el carácter de ser, es la voluntad de poder superior [Dem Werden den Charakter des Seins aufzuprägen, das ist der höchste Wille zur Macht]» (NF 1885-1887, KSA 12, 7(54), p. 312). En Nietzsche, según la interpretación de Heidegger, se asiste a una división, una partición de la propia esencia de la fuerza. El eterno retorno sería el recurso por el cual la voluntad de poder como fuerza autodividida intenta acrecentarse a través de la recuperación de la propia esencia. A partir de su carencia inicial (el no ser completa por haberse escindido) y en la medida en que la fuerza recupera obstáculos que ella misma coloca, ella procede a la fijación de su ser. La voluntad de poder aspira entonces a su acrecentamiento que es sobrepotenciación de sí misma. Por lo tanto, las metas y los valores a los cuales tiende son puestos por ella misma y, además, son inmanentes a ella puesto que no hay nada que la exceda. Para Heidegger, la fuerza tiende así a su recomposición, permaneciendo idéntica a sí misma. Se trata pues de una identidad entendida como una mera igualdad vacía, en términos de Identidad y Diferencia.

Nietzsche tampoco considera que haya un progresar infinito hacia un fin en sí: «Nosotros negamos fines terminales: si el Ser-ahí tuviera uno, ya lo habría alcanzado [Wir leugnen Schluss-Ziele hätte das Dasein eins, so müsste es erreicht sein]» (NF 1885-1887, KSA 6 (71), p. 213). Por el contrario, se trata de un eterno retorno de la misma fuerza, una circularidad, que implica la afirmación de la eternidad de la errancia infinita, que será subsanada por la labor del filósofo artista, creador de valores ya no eternos, sino en tanto ficciones, pasibles de mutación: «Pensemos este pensamiento en su forma más tremenda: la existencia, así como es, sin sentido ni fin, pero retornando en forma inevitable, sin un desenlace en nada: "el eterno retorno". Ésta es la forma extrema del nihilismo: ¡la nada (el sinsentido) eterna!» (NF 1885-1887, KSA 6(71), p. 213).

Heidegger concluye en primer lugar, que la voluntad de poder retorna esencialmente a sí misma, siendo finitas las formas que adoptan sus fuerzas, ya que éstas sólo pueden repetirse. Luego, como no hay estado final del movimiento de su devenir, su retornar es eterno. La fuerza es entonces limitada, fija, la voluntad de poder o carácter 
general del mundo es finito. Para Heidegger esto no implica ni aumento ni disminución, ni tampoco un progreso o desarrollo, sino un devenir, una falta de equilibrio. Siendo el mundo finito, éste es abarcable. Pero «para nosotros», aclara Heidegger, el ente es infinito, o inconmensurable, en el sentido de que sus efectos y fenómenos son no enumerables, por ende, el ente debe hacer que retorne eternamente lo mismo (Heidegger, 2000a, p. 300).

Hasta aquí, la interpretación heideggeriana concibe la eterna repetición como la repetición de la mismidad, pues si no puede haber infinita novedad sino sólo inconmensurabilidad, el ente debe hacer que retorne eternamente lo mismo. Se trata pues, de la circulación eterna de la voluntad de poder. La novedad es sólo una apariencia y se debe sólo a que las variaciones son finitas pero inabarcables para nosotros. Para Heidegger, «lo que deviene no es lo continuamente otro de una multiplicidad que varía sin fin. Lo que deviene es la mismidad misma [das Gleiche selbst], es decir, lo uno y lo mismo (idéntico) en la respectiva diversidad de lo otro. En lo mismo se piensa la presencia en devenir de lo idéntico uno» (Heidegger, 2000b, p. 14, traducción modificada).

Aquí encontramos nuevamente la concepción de la Mismidad como mera identidad consigo mismo de cada uno de los términos de la igualdad, diversos entre sí gracias a sus combinaciones finitas. La identidad y la diferencia son consideradas como "productos" del devenir de "lo mismo". La diferencia es interna a cada uno de los miembros, gracias a lo cual devienen. Como las combinaciones son finitas, la posibilidad de la infinita variación del conjunto queda excluida. A mi entender, por el contrario, la única mismidad es la del devenir como eternamente retornante; un mismo devenir que alberga ya no una dualidad, sino que posee el carácter de la infinita multiplicidad del ser, como se expondrá más adelante.

Heidegger, en sus lecciones sobre Heráclito, interpreta la ya mencionada frase de Nietzsche («Imprimir al devenir el carácter de ser, es la voluntad de poder superior») de la siguiente forma: «La suprema voluntad de poder es querer el devenir, pero estabilizarlo como ser». El ser es entonces consistencia, persistencia, constancia: «Ésta es pensada en el sentido de la metafísica contemporánea como "certeza" y "aseguramiento": el aseguramiento de la consistencia, o sea "el ser" no es solo la voluntad de poder misma, no es "la vida" misma, sino una condición autoimpuesta por la vida misma» (GA 55, pp. 104 y ss.) Heidegger considera que Nietzsche no ha pensado al ser como ser, sino que ha planteado la indiferencia hacia el ser. El hombre se deja barrer por la marea del olvido del ser, pero el olvido mismo ha sido olvidado. Este olvido del ser es el nihilismo denunciado por Heidegger, según el cual el ser «no es nada» (MüllerLauter, 2000, p. 287). Como ya se ha expuesto, la asunción del carácter de ser para el devenir no encierra ninguna certeza, ni aseguramiento de la verdad, sino que es una falsificación, una ficción útil que sirve para hacer formulable el devenir.

Para Heidegger, entonces, el eterno retorno hace posible al ser como consistencia del devenir, como fijo e inmóvil: «El eterno retorno es el más consistente volver consistente de lo que carece de existencia consistente» (Heidegger, 2000b, p. 232). El eterno retorno fija la esencia del mundo que en cuanto caos necesariamente deviene (Heidegger, 2000b, p. 14). De este modo, el eterno retorno es el ser que determina a todo ente en su devenir (Heidegger, 2000b, p. 317). Si este ser pertenece a la voluntad de poder, ésta se asegura su existencia consistente a través de su acrecentamiento, es decir, a través de su devenir. Es la voluntad de poder la que ordena y condiciona «una misma constitución del ente»: la voluntad de poder «dice qué es el ente en cuanto tal, es decir, en su constitución. Con el "qué" está conjuntamente determinado el "cómo" del ser de todo ente». Puesto que, como concluye Heidegger, «el eterno retorno de lo 
mismo caracteriza al ente en su totalidad, es, en conjunción con la voluntad de poder, un carácter fundamental del ser» (Heidegger, 2000b, p. 232). En conclusión, la voluntad de poder determina el retorno del ente como consistencia del ser.

Sin embargo, la propia interpretación heideggeriana del caos refuta, a mi entender, la concepción del retorno del ser como consistencia. En efecto, si con «"caos" [se designa] aquella representación del ente en su totalidad de acuerdo con la cual se considera que éste, en cuanto devenir necesario, posee una multiplicidad de lo que queda originariamente excluida, la unidad y la forma» (Heidegger, 2000a, p. 285), el eterno retorno no puede hacer posible el retorno del ser como fijo e inmóvil, pues carece de las determinaciones necesarias para ello. En efecto, el devenir caótico es un continuo devenir, un eterno fluir de las cosas y del ser en permanente transformación. Su consistencia radica en la acción de determinar el infinito retorno del ente en su totalidad cambiante, es decir, en la constancia de una acción infinitamente repetida. El devenir adquiere de esta manera la consistencia de la repetición impuesta por la voluntad de poder. Lo que retorna tiene en cada caso una existencia consistente únicamente en su ser relativo a la repetición; en su ser en-sí-mismo es, sin embargo, eternamente cambiante, es, por ende, lo por "esencia" carente de determinaciones fijas e inmóviles. Por lo tanto, se debe diferenciar la consistencia del eterno retorno de la supuesta consistencia de aquello que retorna: si la única consistencia es la de una acción, y no la de un carácter, el eterno retorno como voluntad de poder es consistente en virtud de la estabilidad y constancia de su accionar. Siendo así, la voluntad de poder carece de las determinaciones necesarias para determinar el "cómo" y el "qué" de aquello que debe retornar. Adjudicar a lo deviniente el carácter de ser es, como manifiesta Nietzsche, una «doble falsificación, desde los sentidos y desde el espíritu, para conservar un mundo del ente, de lo persistente, equivalente, etc.» (NF 1885-1887, KSA 12, 7(54), p. 312).

\section{Articulación de la voluntad de poder y el eterno retorno. La verdad}

Para Heidegger, la voluntad de poder es representativa, fija lo que es deviniente: «en cada caso tiene lugar un fijar de lo que, de lo contrario, es móvil y en devenir» (Heidegger, 2000b, p. 233). Para Nietzsche, por lo contrario, el mundo no es categorizable por la razón en el sentido moderno, sino que es formulable por la voluntad de poder forjando errores útiles para la vida. La metafísica denunciada por Nietzsche considera al mundo falso, auto-contradictorio, informulable en términos del conocimiento, por lo que necesita la ilusión del ser permanente ${ }^{8}$, un fundamento, una centralidad para hacer formulable el caos y, por ende, dominarlo, introduciendo un orden al que se llama «verdad» ${ }^{9}$. La verdad es una mentira inconsciente admitida por comodidad ${ }^{10}, \mathrm{y}$ tiene su raíz en el olvido de que las así llamadas "verdades" constituyen solamente «metáforas gastadas» y faltas de sentido. La verdad es, pues, «el residuo de una metáfora»

8 NF 1885-1887, KSA 12, 9(89), p. 382: «Der Charakter der werdenden Welt als unformulirbar, als „falsch“, als „sich-wiedersprechend“. Erkenntnis und Werden schliessen sich aus. Folglich muss „Erkenntnis" etwas anderes sein: es muss ein Wille zum erkennbar-machen vorangehn, eine Art Werden selbst muss die Täuschung des Seienden schaffen.»

9 NF 1885-1887, KSA 12, 9(89), p. 382: «die fingirte Welt von Subjekt, Substanz, „Vernunft“ usw. Ist nöthig-: eine ordnende, vereinfachende, fälschende, künstlich-trennende Macht ist in uns. „Wahrheit“ - Wille, Herr zu werden über das Vielerlei der Sensationen.»

10 NF 1887-1889, KSA 13, 11(415), p. 193: «Wir haben Lüge nöthig, um über diese Realität, diese „Wahrheit" zum Sieg zu kommen, das heisst, um zu leben [...]. Dass die Lüge nöthig ist, um zu leben, das gehört selbst noch mit zu diesem furchtbaren und fragwürdigen Charakter des Daseins.» 
(Garrido, 1990, p. 12). Gracias a esta inconsciencia, a este olvido, el hombre adquiere el sentimiento de "la verdad"

Esta "verdad" es pues, una ficción necesaria, una ilusión, por ello, para Nietzsche, el imprimir al devenir el carácter de "ser" es una «falsificación, un error», «una falsificación doble» para retener un mundo de la permanencia. El hecho de que todo retorne es la única constancia que emparenta al devenir con el "ser"12. Este "ser" sin embargo, carece de las connotaciones que la metafísica le ha otorgado, pues es falso (cfr. NF 1887-1889, KSA 13, pp. 46-48), mera ilusión, efecto de superficie. El “ser" debe ser recreado pues carece de permanencia, es efímero. El devenir es pues, una ficción útil y no encierra verdad alguna.

La fuerza inventiva [erfinderische Kraft] que ha imaginado [erdichtet] las categorías, trabaja al servicio de la necesidad, necesidad de seguridad, de comprensión rápida basada en signos y sonidos, de medios para abreviar: - no se trata de verdades metafísicas, en el caso de "sustancia", "sujeto", "objeto", "ser", "devenir"-. Son los poderosos los que han tornado los nombres de las cosas en ley: y entre los poderosos, son los más grandes artistas en abstracción [Abstraktions-Künstler], los que han creado las categorías (NF 1885-1887, KSA 12, 6(11), p. 237).

El problema es que la filosofía es incapaz de cuestionar la necesidad que lleva a acuñar dichas nociones, necesarias para "sostenerse" en el devenir. Este sustrato metafísico se ha vuelto indispensable para los filósofos al punto tal que «parecería que dejáramos de poder pensar, si renunciáramos a esa metafísica» (NF 1885-1887, KSA 12, 6(13), p. 237). En cambio, en la interpretación de Nietzsche, estas mismas nociones, postuladas como ficciones, constituyen errores útiles en aras de hacer formulable la vida.

En la interpretación de Heidegger, Nietzsche relaciona el devenir como ente en su totalidad con el modo en que éste se presencia, es decir, como eterno retorno de lo mismo:

El ente en cuanto tal tiene el carácter fundamental de la voluntad de poder sólo puede ser, en su totalidad, eterno retorno de lo mismo. Y a la inversa: el ente que en su totalidad es eterno retorno de lo mismo tiene que tener, en cuanto ente, el carácter de la voluntad de poder. La entidad del ente y el todo del ente exigen recíprocamente, desde la unidad de la verdad del ente, el modo de su respectiva esencia» (Heidegger, 2000b, p. 230).

La voluntad de poder es el "qué es" el ente en cuanto a su constitución (esencia del ente), mientras el eterno retorno expresa el "cómo es" esa constitución en su totalidad (el modo de su existencia) (Heidegger, 2000b, p. 230). Ambos se articulan, pues el carácter del ente como voluntad de poder se determina como «eterno retorno de lo mismo». En palabras de Heidegger, «sólo a partir de la esencia de la voluntad de poder suficientemente comprendida se vuelve inteligible por qué el ser del ente en su totalidad tiene que ser eterno retorno de lo mismo; y la inversa: sólo a partir de la esencia del eterno retorno de lo mismo es posible aprehender el núcleo esencial más íntimo de

11 NF 1887-1889, KSA 1, Über Wahrheit und Lüge im aussermoralischen Sinne I, pp. 880 y ss.: «Die Wahrheiten sind Illusionen, von denen man vergessen hat, dass sie welche sind, Metaphern, die abgenutzt und sinnlich kraftlos geworden sind. [...] Nun vergisst freilich der Mensch, dass es so mit ihm steht; er lügt also in der bezeichneten Weise unbewusst und nach hundertjährigen Gewöhnungen - und kommt eben durch diese Unbewusstheit, eben durch dies Vergessen zum Gefühl der Wahrheit.»

12 NF 1885-1887, KSA 12, 7(54), p. 312: «Dem Werden den Charakter des Seins aufzuprägen - das ist der höchste Wille zur Macht. Zweifache Fälschung, von den Sinnen her und vom Geiste her, um eine Welt des Seienden zu erhalten, des Verharrenden, Gleichwertigen, usw. Das Alles wiederkehrt, ist die extremste Annäherung einer Welt des Werdens an die des Seins: Gipfel der Betrachtung.» 
la voluntad de poder y su necesidad» (Heidegger, 2000b, p. 38). En efecto, como todo es voluntad de poder y todo fin es inmanente a ella, la voluntad de poder debe retornar eternamente a sí misma, imprimiendo al devenir una circularidad que no puede sino conducir, según Heidegger, al nihilismo. Para comprender la distancia que separa la crítica de Heidegger de los planteos de Nietzsche, es necesario incursionar brevemente en la concepción nietzscheana del eterno retorno y la función que desempeña el amor fati.

\title{
7. Eterno retorno y amor fati
}

En La Gaya Ciencia (1882) Nietzsche plantea la doctrina del eterno retorno por primera vez:

\begin{abstract}
"Esta vida, como tú ahora la vives y la has vivido, deberás vivirla una e innumerables veces más, y no habrá nada nuevo en ella, sino que cada dolor y cada deseo y cada pensamiento y sufrimiento y todo lo indeciblemente pequeño y grande de tu vida deberá retornar a ti, y todo en la misma secuencia y consecuencia [...] también este instante y yo mismo [...]”. Si aquel pensamiento [el alabar al demonio que dijera esto] se enseñoreara de ti, te transformaría en lo que eres y quizás te destruiría; la pregunta en todo y cada cosa: ¿lo quieres otra vez e innumerables veces más? ¡Se extendería sobre tu accionar como el más pesado de los pesos! (Die fröhliche Wissenschaft, par. 341, KSA 3, p. 570).
\end{abstract}

Aquí se abren dos posibilidades: maldecir al demonio o reconocerlo como un dios, rechazar el más grave de los pensamientos o aceptarlo sin exigir nada más. Mientras que el rechazo conduce a la aniquilación, la aceptación conlleva la transformación de la existencia y con ella, la del propio mundo. En efecto, los conceptos de "existencia" y "mundo", son puras «ficciones», el mundo es falso, así como el «carácter de la existencia», la verdad debe ser creada ${ }^{13}$. Tanto el mundo como la existencia encierran infinitas interpretaciones $\mathrm{s}^{14} \mathrm{y}$ por lo tanto, poseen un carácter ambiguo ${ }^{15}$. Nietzsche se pregunta qué alcance tiene el carácter perspectívico del Ser-ahí [Dasein] o si todo «Dasein no es sino esencialmente un Dasein interpretante ${ }^{16}$. "Mundo" y "ser" deben ser por ende reinterpretados o recreados, ya no por un sujeto trascendente al proceso mismo, sino por la conjunción de ambos en el proceso único del devenir. El "sujeto" interpretante, ya no trascendente a la "cosa", se da en la "cosa" y la "cosa" transformada trasforma a su vez al "ser" (Cacciari, 1982, pp. 67 y ss.).

Esta interpretación es avalada por Nietzsche en sus escritos sobre Heráclito. En este autor, Nietzsche rescata la creencia en ciclos repetitivos de ocaso y resurgimiento del mundo transformado a partir del incendio destructor del mismo (Die Philosophie im tragischen Zeitalter der Griechen, KSA 1, p. 829). En otros pasajes retoma el tema

13 NF 1887-9, KSA 13, pp. 46-48: «Aber die Dinge, an welche wir glauben als dauerhaft, sind als solche reine Fiktionen [...]. Der Charakter des Daseins ist nicht ,wahr“, ist falsch [...], man hat schlechterdings keinen Grund mehr, eine wahre Welt sich einzureden [...]. Kurz: die Kategorien „Zweck“, „Einheit“, „sein“, mit denen wir der Welt einen Werth eingelegt haben, werden wieder von uns herausgezogen - und nun sieht die Welt werthlos aus [...].»

14 Die Fröhliche Wissenschaft, par. 374, KSA 3, p. 627: «Die Welt ist uns vielmehr noch einmal „unendlich" geworden: insofern wir die Möglichkeit nicht abweisen können, dass sie unendliche Interpretationen in sich schliesst.»

15 Die Fröhliche Wissenschaft, par. par. 373, KSA 3, p. 625: «Man soll es [das Dasein] vor Allem nicht seines vieldeutigen Charakters entkleiden wollen.»

16 Die Fröhliche Wissenschaft, par. par 374, KSA 3, p. 626: «Wie weit der perspektivische Charakter des Daseins reicht $[\ldots]$ ob [...] nicht alles Dasein essentiell ein auslegendes Dasein ist.» 
del advenimiento y el ocaso del hombre, necesarios para la creación: el hombre debe hacer de sí mismo un retornante y recrearse en el mismo proceso ${ }^{17}$, proceso en el cual se transforma «a través de cien almas» ${ }^{18}$, ése es su destino. Y por fin: volver a querer toda la sucesión. Transformación que ocurre al entrar en el río y que implica haber afirmado el devenir, pues la afirmación produce la «absolución» del río eterno en el cual los hombres entran como iguales a sí mismos ${ }^{19}$. Pero volver a internarse en el río implica internarse en un río distinto ${ }^{20}$, conlleva pues, adentrarse en el devenir cambiante. Por ende, el eterno retorno de los períodos, los eventos y del hombre conlleva su simultánea recreación como acción transformadora de los mismos ${ }^{21}$.

Estas dos interpretaciones antitéticas vuelven a encontrarse en el Zarathustra, pero desde un enfoque diferente. En La Gaya Ciencia, el eterno retorno es enfocado desde las actitudes vitales del hombre en lo que respecta a su revelación: por un lado, la actitud del hombre común que maldice al demonio rechazando el devenir; por el otro, la de aquel que lo acepta transformándose. En el Zarathustra, se hace hincapié en los modos de comprensión del tiempo: desde una circularidad viciosa, donde se asiste resignadamente a la repetición constante de los eventos, o desde una circularidad liberadora a través de la recuperación recreadora de los mismos.

En el apartado "De la Visión y el Enigma", la parábola de los dos caminos opuestos que se reúnen bajo el pórtico denominado "El Instante" describe la unidad de los dos caminos, separados por una eternidad. En el portal se juntan dos largas calles, una hacia el futuro y otra hacia el pasado. Con la vista del portal ha de darse al enano que acompaña a Zarathustra la visión del pensamiento más abismal, el pensamiento del eterno retorno. El enano personifica el punto de vista mundano sobre el tiempo, su concepción como sucesión infinita de ahoras, hacia delante y hacia atrás, que se encuentran en el instante. Esta visión del portal es el enigma, pero no su solución. El enano rechaza la visión rectilínea y propone la de un tiempo circular, en cuyo transcurrir todos los eventos han de retornar tal como sucedieron. La propuesta del enano implica que los hechos y objetos vuelven en su identidad. Zarahtustra pregunta: si es así, «¿no tenemos que retornar eternamente?» ("Vom Gesicht und Räthsel", Also sprach Zarathustra, KSA 4, p. 200). Y agrega: «En cada momento comienza el ser; alrededor de cada aquí rueda la esfera allí. El medio está por doquier. Curvo es el sendero de la eternidad» ("Der Genesende", en "Vom Gesicht und Räthsel", Also sprach Zarathustra, KSA 4, p. 272), aseveración que escapa a la comprensión del enano y de los animales que lo acompañan. Zarathustra rechaza esta interpretación: la develación del enigma pasa por la superación de lo espantoso de la doctrina, por la cual todo parece en vano, toda decisión

17 NF 1882-1884, KSA 10, par. 225, p. 213: «Ihr müsst beinahe zu Grunde gehen [...]. Ihr könnt sonst nicht schaffen, sondern nur absterben. Ihr müsst eure Auf-und Untergänge haben [...]. Ihr ewig Wiederkehrenden, ihr sollt selber aus euch eine Wiederkehr machen.»

18 NF 1882-1884, KSA 10, par. 227, p. 213: «Man muss vergehen wollen, um wieder entstehen zu können - von einem Tage zum anderen. Verwandlung durch hundert Seelen - das sei dein Leben, dein Schicksal: und dann zuletzt: diese ganze Reihe noch einmal wollen!»

19 NF 1882-1884, KSA 10, par 160, p. 205: «Ich lehre auch die Erlösung vom ewigen Flusse: der Fluss fliesst immer wieder in sich zurück, und immer wieder steigt ihr in den gleichen Fluss, als die Gleichen.»

20 Die Philosophie im tragischen Zeitalter der Griechen, 4-5, p. 823: «[...] aber selbst der Strom, in den ihr zur zweiten Male steigt, ist nicht derselbe als bei dem ersten Male.» En la p. 826 vuelve a recalcar que sólo el hombre de corto entendimiento puede creer en la permanencia de las cosas.

21 “Auf den glückseligen Inseln” en Also sprach Zarathustra II, KSA 4, p. 110: «Und was ihr Welt nanntet, das soll erst von euch geschaffen werden.» 
y acción es indiferente, pues de ello sólo resulta el hastío y la negación de la vida ${ }^{22}$, en resumidas cuentas, el fatalismo.

En efecto, Zarathustra no puede remontar el tiempo, pues éste tiene un carácter irreversible. Pero lo que sí puede hacer es tanto afirmar y querer lo no-querido y sucedido, como afirmar lo no-sucedido, decir "sí": «el querer libera [Wollen befreit]» ("Von der Erlösung", en "Vom Gesicht und Räthsel", Also sprach Zarathustra, KSA 4, p. 180). Y Nietzsche agrega: "Todo "lo que fue" es un [...] enigma, un azar cruel — hasta que la voluntad creadora diga: "¡pero así lo quise yo! ¡Así lo querré yo!”-》 ("Vom Gesicht und Räthsel", Also sprach Zarathustra, KSA 4, p. 181). Este afirmar se diferencia de la simple constatación de lo sido, pues al afirmar se asume la totalidad de las opciones o decursos posibles de la vida: tanto lo realmente sido, como lo posible de suceder, tanto lo efectivamente decidido como lo desechado en aras de esta decisión. Entender estos sucesos «no sólo como necesarios, sino como deseables» (NF 1887-1889, KSA 13, p. 493), implica el «amor fati: el que no se quiera nada diferente, no hacia delante, ni tampoco hacia atrás, por toda la eternidad. No solamente soportar lo necesario [...], sino amarlo» (Ecce Homo. Warum ich so klug bin 10, KSA 6, p. 297). Por lo tanto, asumir tanto lo no-querido como lo querido es una redención, una recuperación recreadora y transformadora: «Como poetas, adivinadores y redentores del azar, les he enseñado a crear en el futuro, y a redimir creativamente todo lo que fue» ("Von alten und neuen Tafeln", en Ecce Homo. Warum ich so klug bin 10, KSA 6, pp. 248 y ss.). Se trata de un «querer creativo» (Löwith, 1987, p. 275). En el amor fati, se da la decisión de una "voluntad doble": aquella que prefiere querer la nada a no querer y, además, la voluntad que es capaz de transformarlo todo en el querer. Siendo que el devenir atañe al ser y al mundo en su conjunción, esta transformación implica tanto su reinterpretación como su recreación, ya que su reinterpretación permite asumirlos como nuevos. Sólo el hombre pequeño que se sitúa fuera del proceso no se modifica, pues considera la repetición como una pesada carga, ya que, para él, todo vuelve en forma igual y repetitiva. Por ello el amor fati no es la mera afirmación de lo que se da, sino una afirmación de la vida que implica la negación de todo aquello que pueda constituirse en mera apología de lo existente y a su vez, la afirmación del instante, del azar, del devenir de los "hechos" transformados por el querer.

\section{Heidegger/Nietzsche: ser y verdad}

Habiendo distinguido entre el eterno retorno como retorno de la mismidad y como devenir cambiante, como circularidad viciosa en el primer caso y creativa en el segundo, es posible ahora comprender la distancia que separa la concepción nietzscheana de la heideggeriana: para Heidegger, el ser se articula en la voluntad de poder y el eterno retorno, como se ha visto precedentemente. Debido a que, a los ojos de Heidegger, en el devenir se instaura una falsificación, ese autor concluye que «la verdad sería un error». Pero Heidegger se niega a aceptar el alcance de la destrucción nietzscheana de la verdad, remitiendo al error a un fundamento considerado verdadero: para este autor, la verdad en Nietzsche es una «especie de error» de «apariencia sólo negativa» — la ausencia de metas y valores - que se funda en la determinación positiva y verdadera

22 "Der Genesende", en Also sprach Zarathustra II, KSA 4, pp. 274 y ss.: «Der große Ueberdruss am Menschen [...]: „Alles ist gleich, es lohnt sich Nichts, Wissen würgt!“ [...]. „Ewig kehrt er wieder, der Mensch, dess du müde bist, der kleine Mensch" [...]. Das war mein Ueberdruss an allem Dasein! Ach, Ekel! Ekel! Ekel!» 
del carácter del ser del ente por el cual eternamente retorna como mismidad. Por la misma razón también interpreta el caos como la formación que otorga un orden a la multiplicidad del ente: la falsedad quedaría reducida así a una mera «apariencia», y el caos a una sistematización de las variadas formaciones de poder de la voluntad, con lo cual Heidegger parece así invertir el sentido de las expresiones de Nietzsche. Heidegger mismo reconoce que «sólo si se toma en serio» el pensamiento del eterno retorno como proyecto metafísico, éste resulta terrible, pues una concepción tal no es obra de «una vivencia sólo personal del pensador», ya que tales pensamientos sólo dependen de la historia de la metafísica como ocultamiento/desocultamiento del ser. La verdad del ente sólo puede ser determinada por el ente mismo, continúa Heidegger, cuyo carácter fundamental, la voluntad de poder misma y su inherente sobrepotenciación en el devenir, es el que «pone» el pensamiento del retorno, constituyendo una nueva verdad para la humanidad. La verdad del ente, su esencia, es pues, «el supremo volver consistente de lo que carece de existencia consistente», llevada a cabo por la voluntad de poder (Heidegger, 2000b, pp. 232-235).

Aun cuando Heidegger reconoce que la verdad en el pensamiento de Nietzsche «se ha vuelto hueca» (Heidegger, 2000a, p. 14), y que no es pensada en el sentido de la aletheia en tanto el dejar aparecer en la desocultación lo que está oculto, esto no le impide querer buscar su fundamento en la verdad que para Heidegger «es la corrección del representar» (Heidegger, 2000a, p. 431) — la adecuación del que es y cómo es del ente- De lo antedicho, Heidegger concluye que Nietzsche lleva a cabo el acabamiento de la metafísica, y no su superación - en el sentido del develamiento del ser-, pues «la representación que hace Nietzsche de la misma sigue siendo una representación metafísica signada por la idea de valor» (Cragnolini, 1998a, p. 191), aunque el contenido de la verdad no precise ser verdadero, sino que pueda ser «un engaño, algo no verdadero» (Heidegger, 2000a, p. 431), tenido por tal, creído, por lo que la verdad es sólo una estimación de valor, expresión que Heidegger toma de Nietzsche: «Que es una creencia? ¿Como surge? Toda creencia es un tomar-por-verdadero [Für-wahr-halten]» (NF 1885-1887, KSA 12, 9(41), p. 354). Por lo tanto, Heidegger colige que «está quebrantada la esencia misma de la verdad» en tanto la esencia de la verdad «no precisa ser (algo) verdadero» (Heidegger, 2000a, p. 432).

Esta conclusión no le lleva a considerar a la verdad como ilusión, "producto" de los filósofos, como creencia necesaria para la vida, sino por el contrario, Heidegger se empeña en reconducirla a un principio más originario, método que podríamos llamar de "desplazamiento", que se plantea como menta el encontrar un fundamento para aquello que ha sido "desfondado", absolutizando de esta manera el aspecto estático y fijo del ser frente al devenir. Este principio absoluto lo encuentra en la noción de "valor": la verdad es una estimación de valor, valor en función del crecimiento y de la conservación de la vida ${ }^{23}$, gracias al cual la voluntad de poder se supera a sí misma. En la interpretación heideggeriana la verdad en el sentido de lo fijo, inmutable, estatizado «no es el valor más alto», sino la vida en su devenir (Heidegger, 2000a, p. 441). Heidegger absolutiza el valor, cayendo entonces en un extremo de la oposición y estableciendo una relación de jerarquía y dependencia entre ambos términos. El valor más alto es la vida en su devenir: en la cima de la escala, lo «Uno», la vida, que unifica lo múltiple, el devenir, pero sin consideración de lo variable, lo individual y lo múltiple que está

23 NF 1887-1889, KSA 13, 11(73), p. 36: «Der Gesichtspunkt des „Werths“ ist der Gesichtspunkt von Erhaltungs-Steigerungs-Bedingungen in Hinsicht auf complexe Gebilde von relativer Dauer des Lebens innerhalb des Werdens.» 
implícito en ella, como denuncia Nietzsche (NF 1887-1889, KSA 13, 11 [73], p. 36). Por el contrario, para Nietzsche son ambas instancias - la unificación y multiplicación del sentido - inherentes a la concepción del devenir de la voluntad de poder, por cuanto la unificación del sentido es necesaria para la comprensión, mientras que su multiplicación constituye su aspecto imaginativo o creativo.

Para Nietzsche, «se debe descreer de la verdad», la vida misma obliga a ello. La no-verdad debe ser tomada como condición para la vida: esto implica «desembarazarse de los sentimientos de valor acostumbrados [Wertgefühle], (NF 1885-1887, KSA 12, 35(37), p. 527). La verdad, pues, no deja de ser un sentimiento [Gefühl] y una voluntad [Wille], con la cual el hombre busca «un mundo que no se contradiga, ni engañe, ni cambie, un mundo verdadero - un mundo, en el cual no se sufra: ¡Contradicción, engaño, cambio- causas del sufrimiento! [...] Evidentemente, la voluntad de verdad [Wille zur Wahrheit] es nada más que un anhelo del mundo de lo permanente» (NF 1885-1887, KSA 12, 9(60), pp. 364 y ss.). El cambio es dolor, sufrimiento por enfrentarse con lo heterogéneo, lo imprevisto, el azar, todo lo cual escapa a una razón esquematizadora. Esta «voluntad de verdad» implica la «impotencia de la voluntad de creación [die Ohnmacht des Willens zum Schaffen]», porque opera la reducción de lo múltiple a un fundamento o a «un mundo, como debe ser» (NF 1885-1887, KSA 12, $9(60)$, p. 365), que ignora la contingencia de la vida.

La verdad, por ende, no es algo que deba ser descubierto, sino algo que debe ser creado: el otorgar verdad, como proceso infinito, no es un tomar consciencia de algo que sea «en sí», fijo y determinado, sino una «determinación activa» (NF 1885-1887, KSA 12, 9(91), p. 385). El valor no es algo fijo, un valor transcendente de sentido inmutable, sino que en Nietzsche el valor es sentido provisorio, nunca cerrado sobre sí mismo, no-fundamento. Las verdades creadas son así provisorias. En este sentido, puede interpretarse que Heidegger incurre en este mismo accionar: el de buscar medios y caminos para llegar a un origen verdadero aun cuando en el punto de partida de tal búsqueda deba admitir que en la esencia de la verdad habita, en una primera lectura, una falsedad, una creencia, un "tener por verdadero" (Heidegger, 2000a, p. 431), falsedad que es finalmente desenmascarada como valor que no es sino relativo a las condiciones de la vida. ¡Nada al parecer más extraño al pensamiento heideggeriano que aceptar un fundamento no absoluto, sino supeditado a su utilidad al devenir de la existencia!

\section{Eterno retorno y "subjetividad": ¿mismidad o multiplicidad eternamente variable?}

De lo expuesto anteriormente con respecto a la voluntad de poder como fuerza, parecería instaurarse un movimiento a través del cual la fuerza "da" su ser o parte de él, sólo para recuperarlo e iniciar nuevamente el ciclo: dación/carencia y recuperación/ plenitud. En mi interpretación, en cambio, es la infinita variación de ambas fuerzas en su devenir la que imposibilita la reunificación en la mismidad del eterno retorno.

En efecto, en Heráclito Nietzsche encuentra las raíces de la negación del ser y la negación de la duplicidad de los mundos (Die Philosophie im tragischen Zeitalter der Griechen 4-5, KSA I, p. 822). Existe un mundo único que, como vimos, en ninguna parte revela una «permanencia, una indestructibilidad, una resistencia a al corriente» (Die Philosophie im tragischen Zeitalter der Griechen 4-5, KSA I, p. 283). Por el contrario, «el devenir eterno y único, la completa inestabilidad de todo lo real, que continuamente sólo obra y deviene y no es, según la enseñanza de Heráclito, es una 
visión terrible que aturde [...]. Sería necesaria una fuerza sorprendente para transformar este efecto en su contrario, en lo sublime y en un asombro feliz» (Die Philosophie im tragischen Zeitalter der Griechen 4-5, KSA I, p. 285).

Esta meta fue alcanzada por Heráclito al concebir el devenir como polaridad, como la tensión entre dos fuerzas cualitativamente diferentes y opuestas. Nietzsche se pregunta si Heráclito no recae en la concepción de una dualidad de mundos: por un lado, un mundo de eterna y esencial multiplicidad, de «muchas realidades» correspondientes a multitud de dioses y demonios y, por el otro, un mundo de hombres que sólo ven un mundo en cambio. Cabe la posibilidad también que no sea sino por la debilidad inherente al conocimiento humano que cuando se hable del devenir sólo se entienda una «coexistencia de muchas realidades indestructibles, verdaderas y no realizadas» (Die Philosophie im tragischen Zeitalter der Griechen 4-5, KSA I, p. 287). Se trata de ambas posibilidades a la vez: del juego del mundo, del juego del fuego consigo mismo (Die Philosophie im tragischen Zeitalter der Griechen 4-5, KSA I, pp. 824-828). Este juego es propio de la cultura agonística griega, la contienda, del jugar inocente y amoral del niño y del artista. Por ende, Nietzsche en su lectura de Heráclito adopta la concepción del devenir como polaridad, como la permanente contienda de fuerzas cualitativamente diferentes y opuestas, un juego eterno que impide la instauración del ser como permanencia y fijeza. Por lo tanto, esto invalida la interpretación del eterno retorno como el recurso por el cual la voluntad de poder alcanza la fijación de su ser a partir de una carencia inicial. La voluntad de poder que no es una, sino múltiple y originaria, no "es" en el sentido dado por Parménides, pues sólo deviene ${ }^{24}$.

Por otro lado, en la interpretación de Heidegger, la fuerza tiende a su auto-superación y auto-conservación, y no constituye sino un originario aseguramiento de la esencia. De este modo Heidegger toma la cualidad como un «en sí», soslayando el aspecto cuantitativo de la fuerza destacado por Nietzsche: en efecto, para Nietzsche la voluntad de poder no es sino una multitud de voluntades de poder cuantitativamente diferentes, que se contradicen para prevalecer o subsumir al otro. El quale, la cualidad que es común a todas, puede ser determinada como la voluntad de dominio. La voluntad de poder está constituida por fuerzas, afectos, instintos, que no son el resultado del análisis del sí mismo, de la esencia del ser, como afirma Heidegger, sino que son base y carácter de toda modificación: estos «componentes» conforman el único quale de las diferencias de grado en las cuales se constituye el mundo. La multiplicidad no se deduce de la unidad. Por el contrario, lo simple que sólo puede ser tomado como unidad relacional de organización y juego, es producto de una multiplicidad real (cfr. MüllerLauter 1971, pp. 27-34). Estos «quale» son sólo nuestras «verdades perspectívicas», que no pueden ser reconocidas como comunes ni como verdaderas (NF 1885-1887, KSA 12, 6(14), p. 238).

Para Nietzsche, en efecto, todo el devenir es un fijar relaciones de grado y fuerza, una lucha (NF 1885-1887, KSA 12, 9(91), p. 385). El ego es una «multiplicidad de fuerzas personales» en constante lucha por el dominio. «El punto del sujeto salta», el valor está dado sólo por el quantum de poder, un devenir que carece del carácter de ser, por lo cual los medios de expresión del lenguaje son inútiles para expresar esta fluctuación. «No existe la voluntad, sólo existen puntuaciones de la voluntad, que continuamente aumentan o disminuyen su poder» (NF 1887-1889, KSA 13, II8(3), p. 36). A la

24 Die Philosophie im tragischen Zeitalter der Griechen, KSA I, p. 824: «Das ewige und alleinige Werden, die gänzliche Unbeständigkeit alles Wirklichen, das fortwährend nur wirkt und wird und nicht ist, wie dies Heraklit lehrt, ist eine furchtbare und betäubende Vorstellung.» 
voluntad de poder como esencia se opone la voluntad de poder como pluralismo (cfr. Müller-Lauter, 1999, p. 91). Esto se aplica a todos los seres vivientes, que no constituyen sino «complejos del acaecer (Complexe des Geschehens)» (NF 1885-1887, KSA 12, 9(91), p. 384) que consideran al devenir desde perspectivas múltiples. Sólo son contrincantes temporarios, pues estas formaciones cambian permanentemente. Pero esta voluntad de poder necesita expresarse en oposiciones, busca lo que se le opone. La incorporación del otro es un querer-imponerse, una transformación, hasta que el dominado se encuentre bajo el dominio del atacante y de este modo éste último aumente su poder. Si esta encarnación fracasa, la voluntad de poder se escinde y subsiste como duplicidad, «para no dejar escapar lo que ha sido conquistado» (NF 1885-1887, KSA 12, 9(151), p. 424).

La voluntad de poder carece, pues, de las connotaciones propias de la metafísica del ser heideggerianas, carece de unidad, verdad, esencia. Es, además, inseparable del eterno retorno, pues ella no conforma la esencia de todas las cosas, trascendiéndolas, sino que el «todo» no es más que un complejo fluctuante de agregaciones y desagregaciones de fuerzas, que necesitan entrar transitoriamente en oposición para ejercer su dominio. No hay pues, una voluntad de poder como ente metafísico, sino una multiplicidad de fuerzas: «toda fuerza que tiene un efecto es unívocamente determinable como voluntad de poder [...] el mundo sería justamente "voluntad de poder" y nada más» (Jenseits von Gut und Böse, KSA 5, af. 36, p. 55). No cabe pues, la distinción entre voluntad de poder trascendente y un mundo deviniente, ambos son "lo mismo" en el sentido hedeggeriano, una unidad que no está exenta de las distinciones que realiza el lenguaje, a sabiendas que, en el pensamiento nietzscheano, lo signado por el lenguaje no constituye sino una ficción útil para hacer formulable el mundo.

El "yo" se establece en el entrecruzamiento de esta multiplicidad de fuerzas, constituyéndose en el punto donde estas fuerzas adquieren mayor densidad. Si, como destaca Cragnolini, «yo soy un cruce de fuerzas: las mías, las de los otros, las de la situación y la época, no soy el dominador de "mis" fuerzas». Desaparece, pues, toda idea de dominio de las fuerzas o de actos, toda idea de voluntad dominadora moderna, para restaurar la «vulnerabilidad» de la voluntad a lo «otro», ya sea las otras voluntades de poder, ya sea las circunstancias históricas o de contexto (Cragnolini, 2000, p. 237). Como aclara Derrida en su análisis del «quizás» nietzscheano, cuyas expresiones pueden ser aplicadas al entrecruzamiento de fuerzas eternamente fluctuante, «esta inconsistencia o inconstancia no es una indeterminación, supone un cierto tipo de resolución y una exposición singular al cruce de la ocasión y la necesidad» (Derrida, 1998b, p. 47). En efecto, tanto el recurso al «quizás» como a la fluctuación de las fuerzas supone una indeterminación ajena al pensamiento metafísico tradicional en su búsqueda de certezas.

El "yo" se constituye como cruce de fuerzas, en un "estar presente" en su máxima intensidad, en una experiencia de retorno a sí que tiene lugar en el instante de afirmación del eterno retorno. En esta experiencia de absorción del todo en el presente del instante, no se experimenta un aumento o disminución de poder, tampoco se trata de un acrecentamiento dentro de la mismidad de la voluntad de poder como interpreta Heidegger, sino de un extrañamiento insalvable que desde siempre habita la identidad de la fuerza. En el individuo como pluralidad de fuerzas, habitará desde siempre no sólo una partición, sino también una alienación, debido a que está constituido por fuerzas extrañas, "otras", que varían constante- y eternamente, imposibles de reconciliar y armonizar. 


\section{Eterno retorno y olvido}

Adherir al eterno retorno no supone solamente un «estar presente», sino también el olvido, «pues sólo el olvido permitiría acometer como creaciones nuevas las viejas creaciones, ad infinitum»: en efecto, «volver a querer lo no no-querido por el afán de asumir el hecho consumado, convertirlo en no-consumado, volviendo a pretenderlo innumerables veces» (Klossowski, 1995, p. 73), implica “olvidar" la existencia innegable del hecho para convertirlo en sólo interpretación, de esta manera es posible recrearlo, infinitamente.

Para Heidegger en Ser y Tiempo, el olvido de la propia condición de yecto es característico del «haber sido inauténtico», pues gracias a él, el Dasein evade la responsabilidad de asumir su existencia como una tarea o quehacer. El olvido es, sin embargo, base del recuerdo, pues abre los horizontes dentro de los cuales es posible el recuerdo, o no-recuerdo, el retener o no-retener de los entes intramundanos (Heidegger, 1999, p. 367). El olvido tiene características negativas también en la etapa posterior a la Kehre, pues el olvido de la diferencia entre ser y ente constituye «un velamiento que se ha sustraído desde el principio» y conforma el ámbito dentro del cual se ha desarrollado el pensamiento occidental (Heidegger, 1994b, p. 115). En Nietzsche, en cambio, el olvido es necesario para querer aún lo no-sucedido, por ello, no se trata de "recordar lo sido" o de pensar "lo impensado" a la manera heideggeriana, sino de transformarlo creativamente: «Inocencia es el niño y olvido, un comenzar de nuevo, un juego, [...] un primer movimiento, un decir-sí sagrado» que permite la «creación de nuevos valores». El olvido permite «alcanzar la libertad» necesaria para una «nueva creación» y no sólo para afirmar tanto la necesidad como el azar, lo sido como lo no-sido, lo posible como lo no-posible, lo querido como lo no-querido. En resumidas cuentas, sólo el que por olvido pierde un mundo es capaz de «ganarse» uno propio ("Von den drei Verwandlungen", Also sprach Zarathustra, KSA 4, I, pp. 30 y ss.).

De allí que el instante de la afirmación del eterno retorno, como acontecimiento, se dé como un presente puntual de máxima intensidad y plenitud. Vivir el instante significa no sólo estar en él, sino "ser” el instante. En efecto, sólo para un observador externo, pasado y futuro chocan en un ahora fugaz, en cambio, para el que es el instante, pasado y futuro se resumen en un presente puntual: la eternidad se halla condensada en el presente de un instante. El instante es, pues, decisión: «la voluntad de poder decide el curso del tiempo, aferra su momento, goza el placer del instante» (Cacciari, 1994, p. 133). En él se decide también qué combinación de fuerzas se dará, según una hipótesis que, para Nietzsche, no es mecanicista, ya que no implica un estado final de las fuerzas:

Si el mundo puede ser pensado como una determinada cantidad de fuerza y como un determinado número de centros de fuerza, [...] se sigue que él debe recorrer un número calculable de combinaciones en el gran juego de dados de su existencia. En un tiempo infinito, cada posible combinación sería alguna vez alcanzada; aún más, ella sería alcanzada infinidad de veces. Y como entre cada combinación posible y su próximo "retorno" deberían haberse sucedido todas las combinaciones posibles y cada una de estas combinaciones condiciona la sucesión entera de las combinaciones en la misma hilera, se demostraría un círculo de idénticos casos: el mundo como círculo que a se repitió infinidad de veces y que juega su juego al infinito (NF 1887-1889, KSA 13, 14(188), p. 376).

Como el mundo no ha alcanzado este estado final, «el mecanismo debe valer como una hipótesis incompleta y provisoria» (NF 1887-1889, KSA 13, 14(188), p. 376). Esta hipótesis pareciera implicar que el amor fati se limita a admitir la necesidad del círculo, un querer la vida tal y como se ha dado, es decir, afirmar el instante para que 
retorne como querido. Lo que se decide en el instante, es qué combinación de fuerzas resultarán de la recreación de lo existente; lo que se pone a prueba es la capacidad del hombre para afirmar incondicionalmente la totalidad de lo existente. Pero la afirmación es, a mi entender, más poderosa: ella implica no sólo la aceptación de lo existente, sino de aquellas combinaciones posibles, por lo cual se decide aceptar el ser y no-ser, querer lo no-querido, lo sucedido y no-deseado o no-previsto. Sobretodo implica la recreación y transformación de lo ya dado, por lo que en este juego de combinaciones posibles se introduce la novedad producida por el azar, que impide el retorno de lo mismo y, por ende, refuta una concepción determinista del devenir.

\section{Conclusiones: mismidad, ipseidad y diferencia}

En el instante de la afirmación del eterno retorno, no sólo el hecho cambia para ser "querido" nuevamente, sino también el "yo" cambia, se vuelve "otro" al querer, según lo expresa el aforismo 341 de La Gaya Ciencia: «si aquel pensamiento (el alabar y endiosar al demonio que ordenara vivir la misma vida innumerables veces más) se enseñoreara de ti, te transformaría en lo que eres y quizás te destruiría». En efecto, el querer retrospectivamente implica un desactualizar mi yo para recrearme en la multitud de "yoes" pretéritos y futuros, sabiendo que al hacerlo, no sólo me recreo en vistas al pasado y al futuro, sino en el instante presente. Es decir, la recreación de mí mismo produce la alteridad en mí, no sólo de mis existencias pasadas o futuras de la serie, sino la alteridad en el mismo instante de la creación. Si el "ser" en Nietzsche está compuesto por una multiplicidad de fuerzas, propias y ajenas, en permanente cambio y tensión, y si la aceptación de un momentáneo estado de las fuerzas implica su recreación y reinterpretación, no sólo mi "Selbst" futuro se transforma, sino mi "Selbst" pasado también, pues siendo el tiempo circular, cualquier determinación que se realice tiene un efecto sobre la totalidad de la serie continua del tiempo. Es decir, para poder reinterpretarme en el Instante deberé "olvidar" mi "Selbst", renunciando a él; a la inversa, mi "Selbst sido" es necesario como base para la labor de recreación. Es decir, una vez recreado, querido en lo-ya-sido y lo-por-ser, ya no es posible retornar a mi estado de fuerzas anterior, pues esta recreación implica el recorrer la serie del devenir, por lo cual al retornar he debido transformarme. En Nietzsche, asumir el haber-sido y el por-ser implica asumir un "ser" en tanto una provisoria combinación de multiplicidad de fuerzas irreductibles, una provisoria "mismidad" alcanzada por el Wille que las reúne, sin sintetizarlas. Esto implica que tal vez, mi única posibilidad de reconocerme sea en el querer, en la voluntad, en el deseo de aceptar mi perpetua transformación. Sólo en el Wille, permanezco fiel a mí mismo y "soy" propiamente yo mismo. Mi ipseidad mienta, al igual que en Heidegger, un modo de ser, pero este modo no implica la asunción de la muerte como posibilidad más propia, sino la afirmación del juego de multiplicidad de fuerzas devinientes —el juego de diferencias de fuerzas - que me componen.

En Heidegger y según sus reflexiones de Ser y Tiempo, la temporalidad del «haber sido propio» implica, a diferencia de Nietzsche, una reiteración por la cual el Dasein se vuelve sobre su condición de yecto y asume o toma sobre sí el ente que ya es, es decir, su propia ipseidad (Heidegger, 1999, p. 367). En Nietzsche, en cambio, querer implica renunciar a ser uno-mismo, renunciar a una identidad como constancia de un núcleo determinaciones esenciales. ¿Cómo es posible entonces reconocerse en la inconstancia? Tal vez solamente en la acción del querer: en efecto, deberé "querer" una y mil veces más, deberé, en instantes futuros, desear mi propia transformación. 
Podría sugerirse que mi mismidad se resume al querer, al Wille, al afirmar eternay repetidamente las transformaciones o diferencias que me componen. Este querer no implica una voluntad libre que se impone al devenir, sino una tensión entre una "entrega de sí mismo" al juego del acontecer y una "decisión consciente", que no se limita a ser producto de la labor de una razón que evalúa y sopesa, sino que puede adquirir la forma de una ratificación de una posibilidad de acción o de reacción corporal, motor y afectiva proveniente ya sea de esta razón o de fuerzas, instintos, afecciones o impulsos inconscientes, dependiendo del protagonismo que estas capacidades o "facultades" tengan dentro de la combinación de fuerzas imperantes en el momento de la decisión.

Por lo antedicho podría llegar a plantearse un posible desdoblamiento del yo: aquel que interpreta — sabiéndose él mismo interpretación o sólo consciencia, que para Nietzsche «es solamente un estado de nuestro mundo espiritual y mental» (Die fröhliche Wissenschaft, KSA 3, p. 598) - , circunscripto a su voluntad creadora, y aquellos que son interpretados, sus existencias pasadas y futuras, unificadas en el «Instante» bajo el pórtico. Pero esto supondría una consciencia transcendental husserliana que reflexiona sobre un yo latente convertido en objeto intencional. Esta reflexión presupondría la ideación de un yo permanente y éste a su vez, supondría la reflexión sobre el yo del pasado. En este sentido, en Ser y Tiempo, Heidegger plantea sus reservas al supuesto solipsismo transcendental de Husserl - crítica que ignora la «doble reducción» de la intersubjetividad monádica, concebida ya en 1909/10 25 y expuesta en sus lecciones de Filosofía primera [Erste Philosophie] de 1922/23 (Husserl, 1959, Beilage XX, p. 433, cfr. Breuer 2020) — por el cual todas las experiencias se refieren a un yo y la relación es intencional—. Heidegger se pregunta en Ser y Tiempo:

¿Es de suyo comprensible a priori que el acceso al "ser-ahí" haya de ser una simple reflexión perceptiva sobre el yo de los actos? [... ¿Y si aquella estructura del "ser-ahí" consistente en ser éste en cada caso el mío fuese el fundamento de que el "ser-ahí" no sea él mismo inmediata y regularmente? [en la caída o cotidianeidad]. El yo sólo debe comprenderse en el sentido de un provisional índice formal de algo que quizás se desemboce como su "contrario" [...] sin que el "no-yo" quiera decir en manera alguna otro tanto que un ente por esencia privado del "ser-yo" sino que mienta una determinada forma del ser del "yo mismo", por ejemplo, la pérdida del "sí-mismo" (Heidegger, 1999, pp. 131 y ss.).

En conclusión, y retomando estas expresiones, puede interpretarse que el "serahí" nietzscheano no es en él mismo inmediata y regularmente, pero no en tanto pérdida del "sí mismo" por perderse en la inautenticidad de la cotidianeidad y por no asumirse en su estado de yecto, sino porque esta pérdida de sí mismo es, por el contrario, su ser auténtico y voluntariamente querido en aras de posibilitar su recreación. Por ello, el "yo" nietzscheano debe comprenderse como una ficción, como un "índice formal" en el sentido heideggeriano, de una multiplicidad de fuerzas que mientan un modo de existir, una forma de "ser": la voluntaria pérdida de sí mismo y la constancia de diferencias irreductibles y a su vez variables —en dependencia de la combinación de las fuerzas - reunidas por la mismidad alcanzada por el Wille: en efecto, el "querer" es, en el sentido heideggeriano, una unicidad, pues reúne en el instante la multiplicidad de fuerzas constitutivas del "yo". Sin embargo, este "yo" no es aquel que se mantiene en la multiplicidad de las vivencias, sino un "yo" que gracias al "olvido de sí mismo" puede recrearse, ganando así en multiplicidad de caracteres.

$25 \quad$ El editor de Grundprobleme der Phänomenologie 1910/11 (Hua XIII), I. Kern, aclara que las lecciones se llevaron a cabo en 1909/10 y no en 1910/11, como reconoce Husserl en carta a R. Imgarden de 1924. 
Y esto hay que quererlo, a sabiendas de que un retorno a una mismidad originaria en el sentido heideggeriano es imposible, no sólo porque este "yo" es desde siempre un cruce de fuerzas cambiantes y por lo tanto inestables, sino porque las diferencias son irreductibles a una pertenencia de ser y pensar originarias. Paradójicamente, el "yo" nietzscheano es propiamente él mismo, renunciando a ser él mismo: éste es el poder ser propio que lo singulariza.

\section{Referencias}

BREUER, Irene (2020). "Revisión de la confrontación Heidegger-Husserl. La protocontingencia del mundo de la vida y sus estructuras esenciales" en Investigaciones Fenomenológicas, n. 17, pp. 61-96. https://www2.uned.es/dpto_fim/InvFen/InvFen17/pdf/03_Breuer_Irene. pdf.

BREUER, Irene (2012). "La constitución del sujeto de la experiencia afectiva. Descartes. Nietzsche. Heidegger”, en Investigaciones Fenomenológicas, n. 9, pp. 117-143. https://www2.uned.es/dpto fim/InvFen/InvFen09/pdf/05 BREUER.pdf.

CACCIARI, Massimo (1982). Krisis, Ensayo sobre la crisis del pensamiento negativo de Nietzsche a Wittgenstein. México: Siglo XXI.

CACCIARI, Massimo (1994). "Concepto y símbolo del eterno retorno", en Desde Nietzsche. Arte, tiempo y política. Buenos Aires: Biblos.

CRAGNOLINI, Mónica B. (2000). "Filosofía nietzscheana de la tensión: la re-resistencia del pensar", en Contrastes, Vol. V. Doi: https://doi.org/10.24310/Contrastescontrastes. v0i0.1613

CRAGnOlini, Mónica B. (1998a). Nietzsche, Camino y Demora. Buenos Aires: Eudeba.

CRAGNOLini, Mónica B. (1998b). "Tiempo de la salud, tiempo de la enfermedad", en Escritos de Filosofía, vol. 17, n 33-34, pp. 109-120.

DERRIDA, Jacques (1998a). Memorias para Paul de Man. Barcelona: Gedisa.

DERRIDA, Jacques (1998b). “Amar de Amistad: Quizá - el nombre y el adverbio”, en Políticas de la amistad seguido de El oído de Heidegger. Madrid: Trotta.

DESCARTES, René (1967). "Meditaciones Metafísicas”, en Obras Escogidas. Buenos Aires: Sudamericana.

GARRIDO, Manuel (1990). "Traducción y prólogo", en NIETZSCHE. Sobre vedad y mentira en sentido extramoral. Madrid: Tecnos.

GREISCH, Jean (1994). Ontologie et Temporalité. Esquisse d'une interprétation intégrale de Sein und Zeit. Paris: PUF.

HEIDEGGER, Martin (2003). Aportes a la filosofía. Acerca del evento. Buenos Aires: Almagesto.

HEIDEGGER, Martin (2000a). Nietzsche I. Barcelona: Destino.

HEIDEGGER, Martin (2000b). Nietzsche II. Barcelona: Destino.

HEIDEGGER, Martin (1999). Ser y Tiempo. México: F.C.E.

HEIDEGGER, Martin (1994a). "Die Zeit des Weltbildes", en Holzwege. Frankfurt a. M.: Klostermann.

HEIDEGGER, Martin (1994b). Conceptos fundamentales. Madrid: Alianza.

HEIDEGGER, Martin (1990). Identidad y Diferencia. Barcelona: Anthropos.

HEIDEGGER, Martin (1979). Heraklit (GA 55). Frankfurt a.M.: Klostermann. 
HEIDEGGER, Martin (1967). „Dichterisch wohnet der Mensch“, en Vorträge und Aufsätze. Pfullingen: Neske.

HEIDEGGER, Martin (1948). "De la esencia de la verdad”, en Cuadernos de Filosofía I, pp. 7-23.

HUSSERL, Edmund (1959). Erste Philosophie (1922/23). Zweiter Teil. Kritische Ideengeschichte (Hua VIII). Den Haag: Nijhoff.

KIERKEGAARD, Søren (1976). La Repetición. Madrid: Guadarrama.

KLOSSOWSKI, Pierre (1995). Nietzsche y el círculo vicioso. Buenos Aires: Altamira.

LÖWITH, Karl (1987). "Nietzsche”, en Sämtliche Schriften (NE 6). Stuttgart: Metzler.

MÜLLER-LAUTER, Wolfgang (2000). Nietzsche-Interpretationen. Heidegger und Nietzsche (Nietzsche-Interpretationen; III). Berlin: de Gruyter.

MÜLLER-LAUTER, Wolfgang (1999a). Nietzsche-Interpretationen. Über Werden und Wille zur Macht (Nietzsche-Interpretationen; I). Berlin: de Gruyter.

MÜLLER-LAUTER, Wolfgang (1999b). Nietzsche-Interpretationen. Über Freiheit und Chaos (Nietzsche-Interpretationen; II). Berlin: de Gruyter.

MÜLLER-LAUTER, Wolfgang (1971). Nietzsche. Seine Philosophie der Gegensätze und die Gegensätze seiner Philosophie. Berlin: de Gruyter.

NIETZSCHE, Friedrich (1998). Sämtliche Werke, Kritische Studienausgage (KSA) en 15 Einzelbänden, G. Colli und M. Montinari (Hg.), Berlin: dtv/de Gruyter. Citado como: «KSA»y «NF» (Nachgelassene Fragmente).

PÖGGELER, Otto (1994). Der Denkweg Martin Heideggers. Stuttgart: Neske.

ROMANO, Claude (2017). "L'énigme du Selbst dans l'ontologie fondamentale heideggériene", en Studia Phoenomenologica, XVII, pp. 329-354.

TENGELYI, László (2017). "La pensée historiale de Heidegger dans les Contributions à la Philosophie", en SCHNELL (ed.). Lire les Beiträge zur Philosophie de Heidegger. Paris: Harmattan, pp. 120-140.

VATTIMO, Gianni (1991). Etica de la Interpretación. Barcelona: Paidos.

WALTON, Roberto J. (2001). "La subjetividad como respuesta y centramiento. Multiplicidad y unidad en las figuras del yo", en Naturaleza Humana 2(1), pp. 9-49. 